Landslides (2021) 18:2993-3009 DOI 10.1007/s10346-021-01686-6 Received: 20 October 2020 Accepted: 26 April 2021 Published online: 18 June 2021

(c) Volcano Science Center - USGS 2021

\author{
Mark E. Reid - Jonathan W. Godt - Richard G. LaHusen - Stephen L. Slaughter - Thomas C. \\ Badger - Brian D. Collins · William H. Schulz - Rex L. Baum · Jeffrey A. Coe · Edwin L. Harp · \\ Kevin M. Schmidt · Richard M. Iverson · Joel B. Smith · Ralph A. Haugerud · David L. George
} When hazard avoidance is not an option: lessons
learned from monitoring the postdisaster Oso land-
slide, USA

\begin{abstract}
On 22 March 2014, a massive, catastrophic landslide occurred near Oso, Washington, USA, sweeping more than $1 \mathrm{~km}$ across the adjacent valley flats and killing 43 people. For the following 5 weeks, hundreds of workers engaged in an exhaustive search, rescue, and recovery effort directly in the landslide runout path. These workers could not avoid the risks posed by additional large-scale slope collapses. In an effort to ensure worker safety, multiple agencies cooperated to swiftly deploy a monitoring and alerting system consisting of sensors, automated data processing and web-based display, along with defined communication protocols and clear calls to action for emergency management and search personnel. Guided by the principle that an accelerating landslide poses a greater threat than a steadily moving or stationary mass, the system was designed to detect ground motion and vibration using complementary monitoring techniques. Near realtime information was provided by continuous GPS, seismometers/ geophones, and extensometers. This information was augmented by repeat-assessment techniques such as terrestrial and aerial laser scanning and time-lapse photography. Fortunately, no major additional landsliding occurred. However, we did detect small headscarp failures as well as slow movement of the remaining landslide mass with the monitoring system. This was an exceptional response situation and the lessons learned are applicable to other landslide disaster crises. They underscore the need for cogent landslide expertise and ready-to-deploy monitoring equipment, the value of using redundant monitoring techniques with distinct goals, the benefit of clearly defined communication protocols, and the importance of continued research into forecasting landslide behavior to allow timely warning.
\end{abstract}

Keywords Landslide $\cdot$ Monitoring $\cdot$ Debris

avalanche $\cdot$ Emergency response $\cdot$ Crisis $\cdot$ Oso $\cdot$ GPS

Introduction

On the sunny Saturday morning of 22 March 2014, the Oso landslide (officially called the SR530 Landslide), in western Washington state, USA suddenly collapsed and swept away the Steelhead Haven community located on the adjacent flat alluvial valley floor, dammed the North Fork Stillaguamish River, and buried Wash-

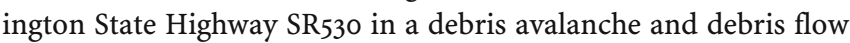
(Fig. 1). Eight people were rescued in the first $2 \mathrm{~h}$ following the slide, and more survivors were found over the course of the day. During the succeeding 5 weeks, as many as 900 workers toiled with hand tools and heavy excavation machinery under the shadow of the slide scar in an intense search, rescue, and recovery operation. Ultimately, the remains of 43 victims were located (SR530 Landslide Commission 2014), making this one of the most deadly landslides in United States history. Only the 1985 Mameyes landslide in Puerto Rico (a US territory) was deadlier with at least 129 fatalities (Jibson 1992).

For many catastrophic landslides, once the rapid movement phase concludes, the overall hazard is reduced. Nevertheless, secondary slope failures may be a concern, and in these cases, expert advice typically calls for restricting access to the landslide area to allow ground conditions to stabilize, subsurface pore-water pressures to decrease, and/or dry weather to ensue. However, these actions are not always possible if rescue or recovery operations are required. At Oso, search and recovery operations began immediately following the landslide and continued for weeks. Because of the need for immediate operations, delay and complete hazard avoidance were not options here. This placed search and recovery workers at risk from additional potential landsliding for an extended period.

Importantly, three other landslide disasters that same year (2014) provide cautionary accounts of the threat to first responders entering areas where recent catastrophic landslides have occurred. On 2 May 2014 in Badakhshan Province, Afghanistan, fellow villagers attempting to rescue victims of a large mobile landslide were buried by a subsequent even larger slide. Hundreds were killed in the two events (Graham-Harrison 2014). In the United States, on 25 May 2014, the West Salt Creek landslide, a fastmoving, high-mobility slide near Collbran, Colorado, collapsed in several phases (White et al. 2015; Coe et al. 2016). Precursory slides occurred in the morning hours, and the apparent blockage of irrigation ditches by these small slides prompted three local residents to investigate. At 5:45 pm, a larger catastrophic rock avalanche/debris avalanche buried the men in a $4.5 \mathrm{~km}$ long deposit (White et al. 2015). Finally, in the predawn hours of 20 August 2014, torrential rains triggered landslides and debris flows in a residential area of Hiroshima, Japan killing 75 people (Asahi Shimbun 2014b; Asahi Shimbun 2015). A veteran firefighter responding to the scene was swept away by a subsequent debris flow while attempting to rescue a 3-year old boy; both were later found dead (Asahi Shimbun 2014a). These tragic examples illustrate that areas subject to catastrophic rapid landslides can pose continuing, sometimes deadly threats to first responders, as well as others in the immediate vicinity.

Landslide monitoring, especially in near real-time, has the potential to provide timely notification of changes in slide motion during a landslide crisis when response actions must take place under hazardous conditions. Here, we use the term near real-time to indicate that data flow has some latency, but the delay is sufficiently short that the data essentially represent current field conditions. In several notable cases, monitoring has led to early 


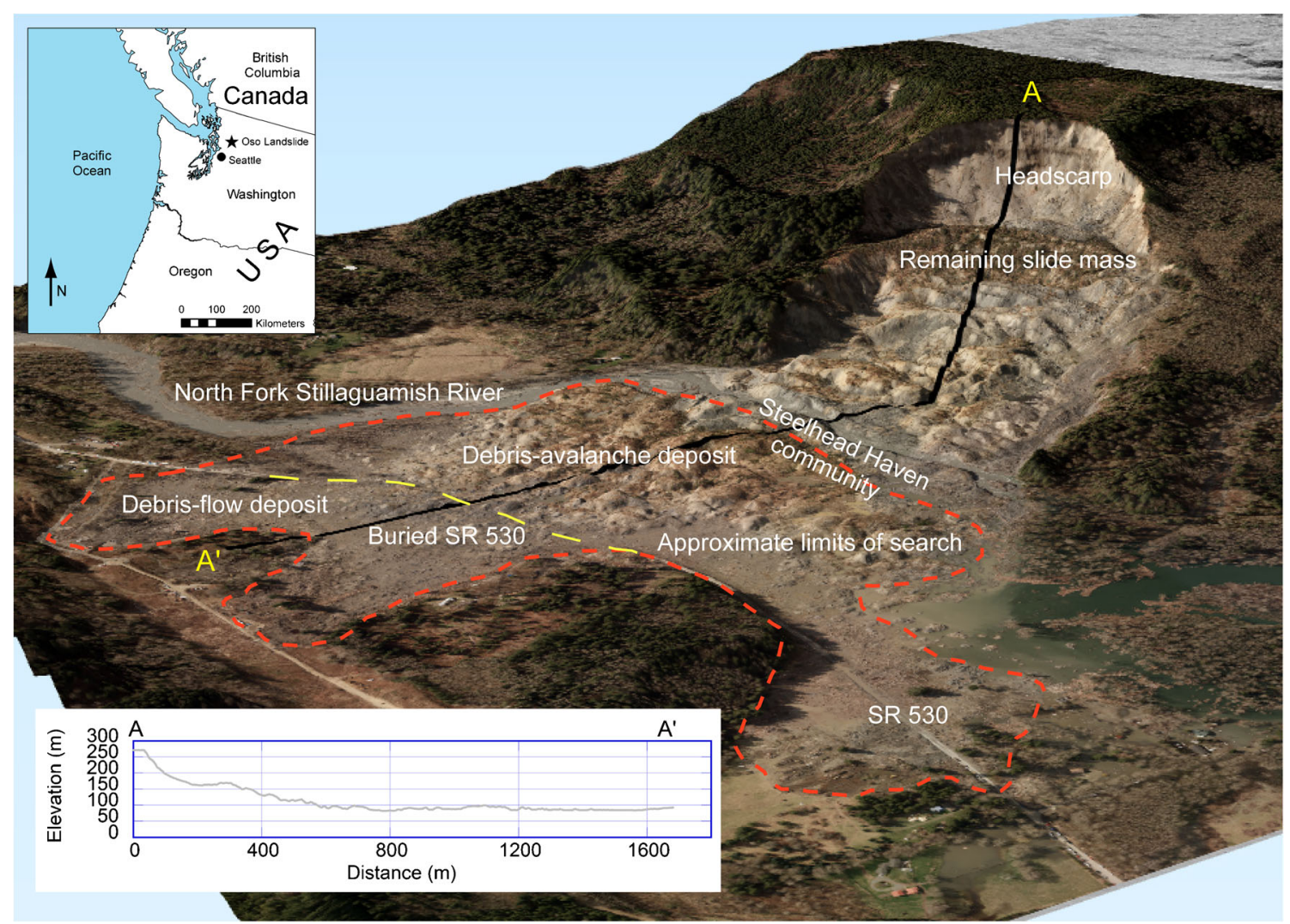

Fig. 1 Oblique view of the 2014 Oso landslide portrayed in an orthophoto draped on postevent lidar-derived topography with inset location map. Bottom inset shows topographic profile with landslide deposit extending $>1 \mathrm{~km}$ across valley flats (no vertical exaggeration). Profile location designated by the black line on orthophoto. Approximate area of search operations outlined in dashed red. Lidar (6 April 2014) and orthophoto (14 April 2014) acquired by WSDOT

warning of imminent catastrophic failure and likely prevented loss of life (e.g., Rose and Hungr 2007; Keys and Green 2008; Pankow et al. 2014; Loew et al. 2016; Intrieri et al. 2019). Over the last several decades, near real-time monitoring systems have been increasingly deployed to provide situational awareness for both slow and rapid landslides (e.g., LaHusen 2005; Read et al. 2005; Yin et al. 2010; Intrieri et al. 2012; Malet et al. 2013; DeGraff et al. 2015). A wide variety of field instruments and techniques are available to monitor landslide deformation and movement (e.g., Dunnicliff 1993; Mikkelsen 1996; Angeli et al. 2000; Casagli et al. 2010; Jaboyedoff et al. 2012; Mazzanti 2012; Dick et al. 2015; Scaioni 2015). Yet more components are needed for these observations to be useful for emergency response decisions, such as issuing evacuation orders. Efficient data dissemination is required to transmit information about current conditions from the landslide site to users in a form that can be easily interpreted (e.g., Reid et al. 2008; Allasia et al. 2013; Intrieri et al. 2013; Froese and Moreno 2014; Pecoraro et al. 2019). Further, such information must be recorded, interpreted, and transmitted prior to catastrophic failure with detection thresholds capable of providing advance warning that allow sufficient time for evacuation of endangered personnel.

For landslides with the potential to fail catastrophically but having limited spatial and temporal monitoring, various methods based on observed changes in ground-surface displacements, velocities, and accelerations are typically used to evaluate activity and potentially estimate a time of rapid failure (Eberhardt et al.
2012; Intrieri et al. 2019). However, complexities and uncertainties in geologic settings, such as failure modes, material properties, failure geometries, kinematics, and variable driving forces, make definitive warning criteria elusive and have led to mixed forecasting success (e.g., Dick et al. 2015; Intrieri and Gigli 2016). Despite these uncertainties, some generalizations have emerged. One is that landslides controlled by reductions in strength or progressive failure typically do not instantly undergo rapid movement, as might occur during an earthquake-triggered event. Instead, they are in motion and usually accelerating prior to rapid failure. The time period of precursory acceleration can range between weeks or months for larger slides such as Vajont, Italy (Kilburn and Petley 2003) to hours for smaller slides (Fukuzono 1990; Dick et al. 2015). A related caveat is that some landslide acceleration, in itself, may be a false alarm and does not necessarily indicate that rapid failure is imminent (Eberhardt et al. 2012). The bottom line is that during a rapid response to a new landslide crisis, there are guides but no foolproof methods or algorithms to forecasting subsequent behavior.

Following the 2014 catastrophic Oso landslide, multiple government agencies (including Snohomish County, Washington State Department of Natural Resources (WADNR), Washington State Department of Transportation (WSDOT), and the U.S. Geological Survey (USGS)) cooperated to design and implement a multifaceted monitoring system aimed at detecting potential large-scale sliding that could threaten the on-going search and recovery 
operations. We rapidly instituted diverse and redundant monitoring procedures, including the following: (1) continuous on-site observation by time-lapse camera and trained geologists; (2) periodic terrestrial laser scans and total station surveys; (3) repeat aerial photogrammetry and lidar scans; and (4) continuous near real-time data streams from extensometers, GPS receivers, and seismometers. Our effort is notable because it required continuously cataloging, evaluating, and interpreting incoming near real-time monitoring data over the weeks in which hundreds of recovery workers labored on the landslide deposit. In this situation, avoidance of the hazard was not an option. Here, we briefly describe the landslide event, review our landslide response efforts and monitoring techniques, and discuss the lessons we learned. Our intent is to provide a case study that illuminates the successes and challenges of using landslide science to support emergency management and search and recovery operations. Landslide crises are unfortunately inevitable, and lessons from our response could help guide preparation for future events.

\section{Landslide characteristics}

Located about $100 \mathrm{~km}$ NNE of Seattle on the western edge of the Cascade Range, the Oso landslide initiated from a $\sim 180-\mathrm{m}$ high terrace of stratified glacial and proglacial deposits (Dragovich et al. 2003; Riemer et al. 2015) perched above the north bank of the North Fork of the Stillaguamish River (NFSR). Despite the relatively low relief of this terrace, the slide mass traveled rapidly $\sim 1 \mathrm{~km}$ across the flat adjacent alluvial valley (Fig. 1). In places the leading edge of the slide (which had the character of a debris flow) reflected backwards when it encountered the opposite valley wall. The slide exhibited a high degree of mobility compared to other debris slides and avalanches, with a maximum height $(\mathrm{H})$ to total travel distance (L) ratio of 0.105 , and had a volume initially estimated at $\sim 8 \times 10^{6} \mathrm{~m}^{3}$ covering an area of $\sim 1.2 \mathrm{~km}^{2}$ (Iverson et al. 2015). A subsequent analysis informed by exploratory drilling estimated a total slide volume of $\sim 9 \times 10^{6} \mathrm{~m}^{3}$ (Collins and Reid 2020).

The Oso slide deposits encompass a wide variety of morphological styles, as described elsewhere (Keaton et al. 2014; Iverson et al. 2015; Wartman et al. 2016; Aaron et al. 2017; Perkins et al. 2017; Stark et al. 2017), and explored further in a detailed fieldbased investigation into the causes of its mobility (Collins and Reid 2020). Here, we focus on aspects of the slide that directly affected the landslide crisis response during the 5 weeks following the event, rather than on details learned through later investigations. Overall, the deposits transition downslope from a rotational slump mass adjacent to the $\sim 100 \mathrm{~m}$ high headscarp to extended coherent extensional slide blocks to debris-avalanche hummocks to a thin debris-flow deposit at the distal margin (Fig. 1). Most of the deposit covering the alluvial floodplain consists of debrisavalanche hummocks ranging up to $\sim 10-20 \mathrm{~m}$ in height and decreasing in size away from the landslide source, with a thin veneer of debris-flow material in the southern distal regions. Nearly all the slide deposits exhibit signs of extension, including tension cracks, grabens, and hummocks. Although the overall slide displays a variety of movement styles, some researchers have termed it a debris avalanche-flow (Iverson et al. 2015), in part because avalanche and flow materials were the most mobile and now occupy large areas of the valley floor. The combined debris avalanche-flow phenomena destroyed and buried the Steelhead Haven community previously situated on the valley flats.

The landslide area had experienced repeated episodic movements since at least the 1930s, with the most recent activity in 2006, referred to as the Hazel landslide (Thorsen 1969; Miller and Sias 1997; Miller and Sias 1998). These historical movement episodes primarily affected the terrace hillslope and the river at the base of the slope. None extended across the alluvial flats to the other side of the valley. Immediately following the 2014 event, mapping using preevent aerial lidar-derived topography from 2013 revealed the presence of multiple prehistoric landslides with deposits extending well across the valley flats (Haugerud 2014). A notable example, termed the Rowan debris avalanche-flow (Iverson et al. 2015), exists $<1 \mathrm{~km}$ downstream of the Oso landslide and had been identified in earlier regional geologic mapping (Dragovich et al. 2003).

Although the slide occurred on a sunny morning and precipitation over the prior several days was light, previous rainy periods likely contributed to failure and to the mobility of the landslide mass. The 21- to 42 -day periods prior to the event had anomalously high precipitation; over the prior 21 days about $334 \mathrm{~mm}$ of precipitation was recorded near Oso (Henn et al. 2015). Previous years were wet as well and could have preconditioned the slope to failure; the previous 4-year period (ending on 31 March 2014) was the wettest on record (Iverson et al. 2015). However, the response between rainfall infiltration and increased groundwater pressures at depth can be delayed and nonlinear (e.g., Iverson 2000; Lu and Godt 2013), making it difficult to directly relate this failure to a specific wet period without measurements of pore-water pressures on, or in the vicinity of, the imminent landslide failure surface. Alternatively, progressive failure may have occurred in intact lacustrine sediments with negligible precipitation response on subsurface pore pressures (Badger and D'Ignazio 2018). Regardless of the initiation mechanism, wet materials can aid the transformation from slide into debris flow, and thereby enhance mobility and increase destruction in the runout path (e.g., Iverson et al. 1997).

Ground shaking records from the Pacific Northwest Seismic Network documented the timing of failure, commencing at about 10:37 am local time in an energetic burst with long-period motions that lasted about 2.5 min (Allstadt et al. 2014). A second high-frequency shaking event occurred about 4 min following the initial burst. Subsequent seismic analyses show that the vast majority of force associated with slide movement was exerted during the first seismic event, whereas movement of a smaller mass created the second period of shaking (Hibert et al. 2015; Iverson et al. 2015). From an immediate hazardsmonitoring perspective, failure occurred rapidly with no obvious seismic precursors and could have potentially done so again, thereby threatening recovery workers.

\section{Response to the landslide crisis}

As the landslide crisis evolved, so did emergency management goals and interpretations of landslide behavior. Fluctuating conditions necessitated adaptive strategies to help mitigate ongoing risks. This was particularly critical as search and recovery operations continued for about 5 weeks with hundreds of personnel working in the valley directly downslope from the landslide headscarp (Fig. 1). The pressure of a grim search situation, the uncertainty of additional massive landsliding, and the lack of avoidance options to ensure worker safety generated a stressful and challenging environment for geologists responding to the crisis. 
Immediately following the catastrophic collapse on March 22, search and rescue units from county, state and federal agencies responded, with multiple helicopters airlifting a total of 11 survivors that day. The scale of the disaster prompted a declaration of a state of emergency by the governor of Washington State. The Incident Command System (ICS), used worldwide for disaster management, was implemented to manage the massive landslide crisis. Within this system, landslide experts from a consortium of government agencies were requested to provide technical assistance to an Incident Management Team (IMT). The IMT, with both liability and chain-of-command issues in mind, controlled who provided technical assistance. The IMT, in turn, was responsible for directing search, rescue, and recovery operations.

The day following the collapse, geologists from the WADNR performed the first of several reconnaissance overflights to assess the extent of damage and the potential for future movement. Initial concerns focused on flooding, as the landslide dammed the NFSR (Fig. 2a) and a lake formed upstream and flooded homes that were not impacted by the landslide itself. In addition, catastrophic failure of the landslide dam could potentially have caused downstream flooding. Fortunately, the landslide dam did not fail rapidly. Rather the river overtopped the debris and incised a narrow channel into the hummock field on March 24 (Fig. 2b). Although an elevated water pool behind the landslide dam remained for the next month, subsequent excavation operations enlarged the existing channel through the slide debris allowing lake drainage and increasing the flow of the NFSR. Further details of postevent NFSR behavior can be found elsewhere (Anderson et al. 2017).

Preliminary geologic reconnaissance conducted by WSDOT, WADNR, Snohomish County, and the USGS immediately after the catastrophic landsliding concentrated on event characterization to inform response efforts. On March 24, 2 days after the occurrence of the main slide, the first postslide aerial lidar and orthophotographs of the site were acquired by WSDOT. That same day a small slope failure on the main headscarp, as noted by onsite workers, prompted temporary evacuation of rescue workers from the slide area. Clearing the entire area was not rapid; it required several hours and reflected the difficulties of working in partially liquefied slide debris. Also on that day, United States President Obama issued a Federal Emergency Declaration which enabled the Federal Emergency Management Agency (FEMA) to bring additional resources and federal personnel to the emergency operations. During these early times, a tactical science team covering both flooding and landslide hazards was formed and information relayed through a liaison geologist to the Incident Management Team (IMT).

As the response unfolded, the enormity of assessing ongoing multiple hazards prompted a separation of the tactical science team into two teams, with one focusing on landslide issues and the other on flooding. Beginning on March 26, the Landslide Monitoring Team (with members from Snohomish County, WADNR, WSDOT, and USGS) began holding daily landslide coordination calls among county, state, and federal geologists and engineers on site and those located in their respective regional offices. Geologists on site examined continuing landslide hazards posed from slopes adjacent to the search area, with daily on-theground field reconnaissance of the landslide margins and the headscarp region. Based on these observations, geologists initially identified four slope-failure scenarios that could generate fartraveled slides with the potential to impact search operations: additional failure of the headscarp area; additional failure of the slope adjacent to the western landslide flank; continued, possibly rapid reactivation of the remaining landslide mass on the slope; and possible generation of smaller debris flows from the upper eastern flank. Early in the response, these smaller debris flows could have generated waves in the lake formed by damming of the NFSR and thereby impacted rescuers searching for victims. Moreover, concerns about the potential for additional large failures were heightened with the publication of the lidar-derived map of nearby prehistoric landslides available 5 days after the Oso event (Haugerud, 2014), and with preliminary assessment of nearby landslide hazards as presented by Badger (2015). These assessments indicated that multiple past failures in this region had been highly mobile and suggested that subsequent failure of the Oso headscarp or adjacent areas might produce failures capable of reaching recovery workers.

Crucial questions involved the deployment of search and rescue efforts: both where to focus search energies and where to avoid continuing hazards. Geologists, using field observations and interpretations of aerial imagery and high-resolution topography, provided information about both of these issues to guide decisions by emergency managers. On March 29, geologists established a "nogo" management line (Fig. 3) to delineate areas directly beneath the landslide headscarp at the greatest risk from further large-scale landsliding. This line was located south of both the new river channel and high hummock deposits, about $1000 \mathrm{~m}$ from the headscarp. During search operations, ground access upslope of the no-go line, as well as airspace access to the landslide area, was severely restricted for safety reasons. Geologists were granted access above the main headscarp, with additional protocols such as safety ropes, to visually monitor the slide and to install monitoring devices. Geologic investigations during this time were limited to those that contributed directly to the missions of the tactical science teams and emergency managers.

The Oso landslide event swept homes, vehicles, and their contents across the valley floor and away from the steep slope on the northern slide of the NFSR. Geologists advised search and rescue workers to focus their pursuit of buried victims on distal debris fields near the landslide deposit margins. Maps and GPS-enabled locator systems installed in search helicopters that identified original home locations were less useful, as most victims had been swept to the deposit margins by the debris-flow front. Moreover, landslide deposit thickness maps created using pre- and postevent lidar elevation differences showed that the former locations of homes were buried under more than $10 \mathrm{~m}$ of slide debris, more than could be quickly and safely excavated given the unstable conditions of the deposit (Fig. 3). To help identify search targets, USGS researchers used the D-Claw model to simulate the dynamics of the landslide (Iverson et al. 2015; Iverson and George 2016). On April 4, animations of preliminary simulations were shown to search personnel in the field and these animations were soon available on the internet (https://www.youtube.com/ watch?v=2NzHCOhKr7g and https://www.youtube.com/ watch?v=Gj-7AyVwqZo).

Recovery efforts progressed for weeks following the initial landslide event. The landslide disaster's status was elevated by a Presidential Major Disaster Declaration on April 2, allowing 

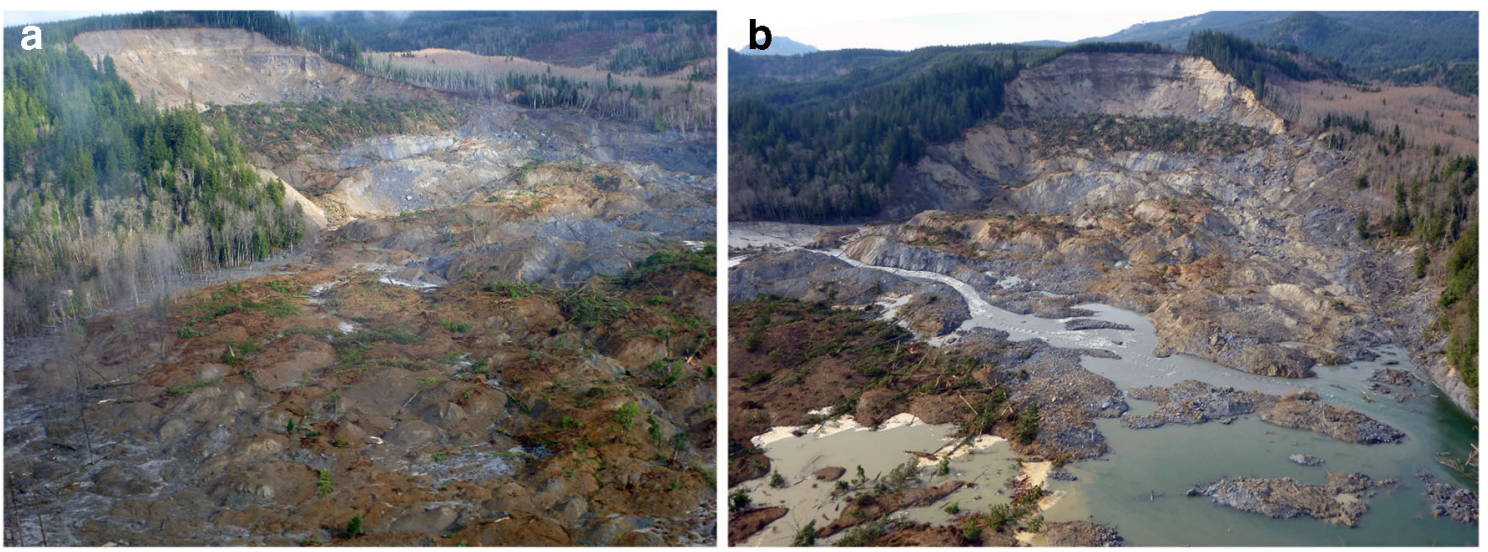

Fig. 2 Photographs taken 1 day apart showing (a) before and (b) after the North Fork Stillaguamish River incised through the Oso landslide deposit. Photos by S. Slaughter (WADNR) taken on 23 March (a) and 24 March 2014 (b), from slightly different view angles

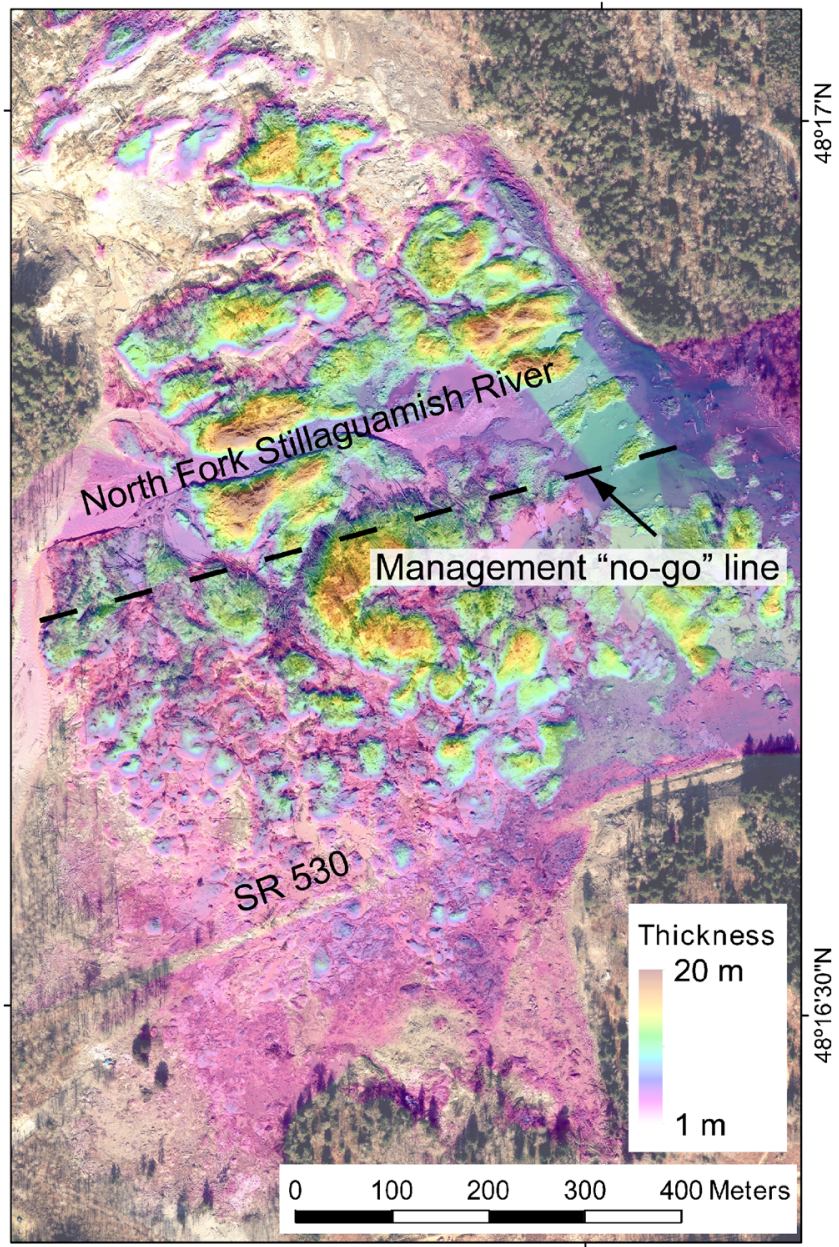

$-121^{\circ} 50^{\prime} 30^{\prime \prime} \mathrm{W}$

Fig. 3 Topographic elevation difference image of the Oso landslide deposit created using pre- and postevent lidar-derived digital elevation models. The management "nogo" line was defined to limit search and recovery operations to an area beyond the estimated reach of additional large-scale landsliding. Original figure cautioned against using thicknesses north of the river to estimate deposit thickness, as this area contained remaining landslide mass. This image was available to emergency managers several days after the event 
additional FEMA funds to aid recovery efforts. Official efforts to recover the remains of landslide victims continued on-site until April 28, when all but one of the 43 victims had been located. On June 20, highway SR530 reopened and on July 14, continued local recovery efforts found remains of the last victim (SR530 Landslide Commission 2014).

A fundamental change in landslide response strategy occurred over the first few weeks following catastrophic sliding. Although survivors were found on the day of the event, within a few days the initial search and rescue operations morphed into a massive recovery operation with hundreds of workers striving to exhume victim remains using hand tools and dozens of mechanical excavators (Fig. 4). This transition accelerated when Washington State Governor Inslee, in a meeting with local residents on March 30, supported a goal of recovering all victims. This goal extended recovery work and precluded simple avoidance of the continuing landslide hazard.

\section{Landslide monitoring}

\section{Purpose}

Our overall goal was to provide as much reliable information about landslide behavior as possible to inform decisions being made by others, namely, emergency managers overseeing search and recovery operations. The objective was not reconnaissance or exploratory science but rather science to support decision making, similar to that used during volcano eruptions (e.g., Williams et al. 2020). This differed from typical postevent factfinding missions. Within a week of the Oso landslide event, concerted efforts began to continuously monitor both postevent landslide movement and precursory signs of movement on adjacent hillslopes. Monitoring was crucial to detect and track changes in landslide behavior. Several intertwined issues prompted calls for continuous monitoring of the Oso landslide activity, including (1) uncertainty about slope instability potentially affecting the disaster site; (2) new landslide mapping that indicated the potential for other large failures (Haugerud, 2014); (3) an increase in field personnel and their exposure time to meet recovery commitments; and (4) the extended time needed to potentially evacuate recovery personnel if precursory landslide activity was detected. This latter point emphasized the need to analyze longer-term movement trends to aid advance notification.

Because recovery operations began immediately following the initial collapse, a landslide monitoring/warning system needed to be quickly operational to provide information in a timely manner. Multiple agencies involved in the postslide assessment activities (Snohomish County, WADNR, WSDOT, and USGS) had previous experience utilizing different techniques to monitor ground deformation. Because of these established capabilities, each agency could rapidly bring different dedicated monitoring abilities to a joint multiagency monitoring effort. Moreover, both the USGS and WSDOT had previous experience providing near real-time monitoring data from active landslides and large excavations (Reid and LaHusen 1998; Harp et al. 2008; Reid et al. 2008; Badger et al. 2011; Norrish et al. 2011; Reid et al. 2012). However, questions remained about how long such monitoring operations would continue. Initial estimates were for "about 2 weeks" and this time frame affected decisions about which techniques could be rapidly deployed and implemented. Official recovery operations, however, lasted considerably longer-more than 5 weeks (Fig. 5).

\section{Monitoring design}

Although a variety of field monitoring techniques formed the backbone of the monitoring effort at Oso, development of a complete alert system required several key components to provide reliable information for decision making and subsequent actions. A complete, end-to-end early warning system should include the following: (1) knowledge of specific hazards and risks; (2) the ability to detect, monitor, assess, and forecast hazards; (3) procedures to disseminate timely, authoritative knowledge with actionable warnings; and (4) preparedness at all levels (UN Working Group 2016). At Oso, despite our imperfect knowledge of potential slide behavior, we needed to quickly deploy monitoring utilizing readily available monitoring and forecasting capabilities. Our primary monitoring objectives were to identify precursory indications of large-scale upslope movement that might portend a subsequent failure large enough to reach recovery operations in the NFSR valley. Monitoring to detect lower-threat, smaller potential failures from the recent headscarp or slide margins was less of a priority. As such, our techniques relied on detecting groundsurface displacement or acceleration over time that might reveal changes in velocity or acceleration in regions upslope or adjacent to the March 22 failure. An immediate collapse, such as that triggered by strong earthquake ground shaking, would not have such precursory signals. To reveal evolving spatial patterns, as well as longer-term temporal trends in movement, we opted for a variety of redundant techniques to detect displacement, in the event that a specific technique provided spurious or incomplete information. Because time scales for changes in motion can vary from weeks to hours, we implemented both near real-time and repeat assessment monitoring methods spanning a range of update frequencies from seconds to days (Figs. 5 and 6).

Providing timely notification of landslide activity in this ongoing emergency situation required actionable communication and notification protocols. The basic chain of communication began with the Landslide Monitoring Team, with members from Snohomish County, WADNR, WSDOT, and the USGS, communicating through a defined geologist liaison (from WADNR) to the Incident Management Team. Once near real-time data flows were established, USGS personnel took the lead on continuously monitoring these data during the working daylight hours of the recovery operation every day of the week. We defined four levels for notification of landslide activity, with communication protocols varying depending on landslide activity tailored to the specific Oso situation (Table 1). Protocols ranged from daily summaries for the Incident Commander if there had been no slide activity of concern, to immediate direct communication with field commanders if large-scale activity was noted and evacuation of field personnel was warranted. Recovery operation personnel had defined procedures for emergency evacuation from the site that could be triggered by radio communications or on-site audible sirens for notification of impending additional landslide movement.

Continuous near real-time data streams were aggregated onto a web-based dashboard that summarized and displayed current conditions in synch with the near real-time data feeds; this information was available over the internet to all members of the Landslide Monitoring Team. Teams of two USGS geologists, which 

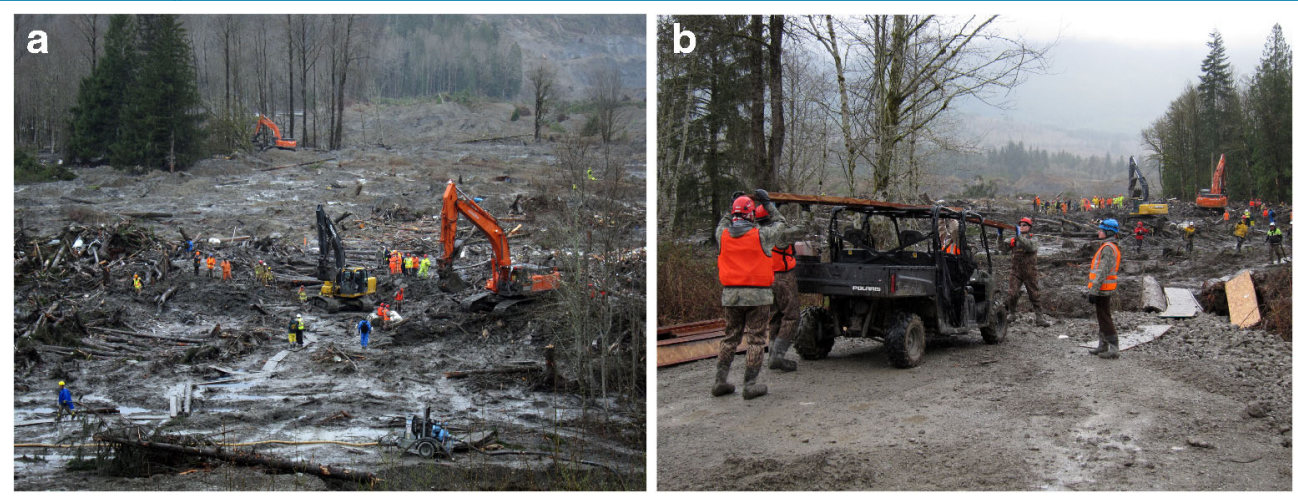

Fig. 4 Photographs of recovery operations on distal part of landslide deposit. Photos by M. Reid (USGS) taken on 30 March 2014

rotated on an overlapping 2-week schedule, conducted continuous surveillance of the data and activities - initially at the nearby Incident Command Post and later remotely via the internet. Overlapping schedules allowed for cross training on instrument setups and on-going landslide behaviors. Operational roles and responsibility checklists for these observers were clearly defined. Also during the recovery working hours, another rotating geologist from WADNR was stationed at the Engineering Observation Lookout (Fig. 6) for continuous visual observation of on-site conditions. This geologist had direct radio links to both the Landslide Monitoring Team and field operation commanders and could request immediate evacuations. In addition, this geologist would issue short descriptions via radio immediately following any debris falls from the main headscarp. These statements served to reassure first responders that someone was watching and aware of slide activity. Both of these observational activities continued until official recovery operations ended on 28 April 2014.

\section{Near real-time monitoring methods}

We implemented several near real-time systems to monitor postevent landslide movement. One system, deployed by WSDOT, relayed surface extensometer and precipitation data from the area above the main headscarp every 5 min (see Fig. 6 for locations). Ground displacement (extension) or acceleration of this region might have indicated the start of a large retrogressive failure. This system utilized six UniMeasure JX-PA extensometers $(50-\mathrm{cm}$ range) with steel cables protected by PVC pipe and installed in three transects, a NovaLynx tipping bucket rain gauge (o.o1-inch resolution), a Campbell Scientific CR10oo data logging system, and cellular telemetry. Automated data collection was performed in LoggerNet software (Campbell Scientific), with data processed, stored, and web-accessible via server-based ARGUS Monitoring Software (Interfels).

A second near real-time system, installed by the USGS, used three GPS-seismometer "spider" units to monitor the area above the headscarp, to the west of the slide (to detect any impending adjacent activity that could reach recovery operations), and the failed remaining main slide mass (see Fig. 6). We remotely deployed the spider units using helicopter sling load techniques. The battery powered spider units consisted of self-contained tripodmounted instrumentation vaults with on-board L1-only GPS receivers, external seismometers/geophones, and dedicated spreadspectrum radio telemetry (Fig. 7). The data acquisition system and seismic waveform digitizer for the spiders were designed and

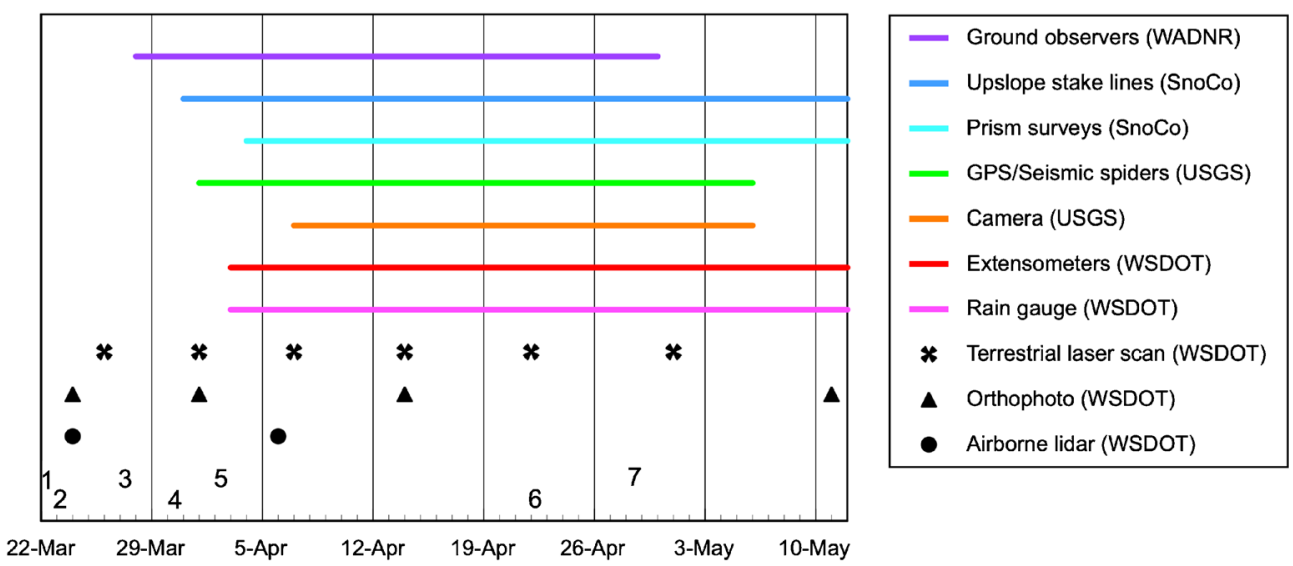

Fig. 5 Timeline of near real-time and repeat-assessment monitoring activities during the 2014 Oso landslide response. Bottom row of numbers indicate select events described in text: (1) landslide occurrence; (2) North Fork Stillaguamish River incises through landslide deposit and Federal Emergency Declaration; (3) release of landslide lidar mapping (Haugerud 2014); (4) Washington State Governor Inslee meets with local residents; (5) Federal Major Disaster Declaration; (6) U.S. President Obama visits landslide; and (7) end of official recovery efforts. SnoCo is Snohomish County Public Works 


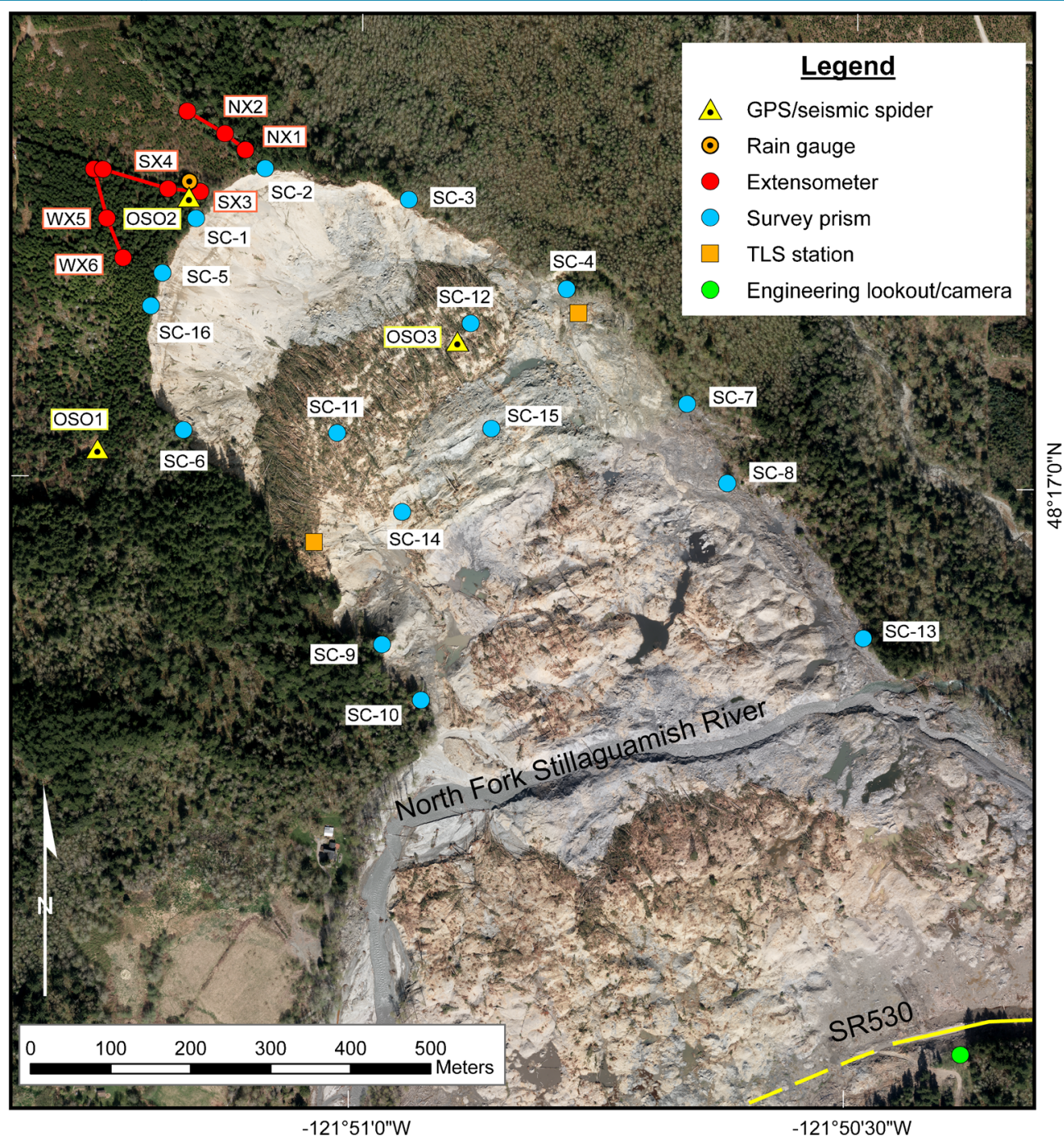

Fig. 6 Locations of monitoring instrumentation during the 2014 Oso (SR530) landslide response, as of 19 April 2014. TLS station denotes terrestrial laser scanning setup locations. Orthophoto base acquired by WSDOT (14 April 2014)

developed by the USGS. Spiders were initially designed to monitor active volcanoes such as Mount St. Helens (LaHusen et al. 2008), but have also been used to monitor active landslides (Harp et al. 2008; Reid et al. 2012). At Oso, GPS data received by the spiders were collected every $15 \mathrm{~s}$ using u-blox $\mathrm{T}_{4}$ GPS receivers with Trimble Bullet antennas. These data were continuously transmitted by cellular telemetry to an offsite USGS server. Static, fixed ambiguity positions for each 15-s epoch were automatically computed (using Waypoint GrafNav software, version 8.1) nominally every $10 \mathrm{~min}$. Each computed position used GPS satellite observations from the previous 3 -h period. Computed differential positions (est. accuracy $<2 \mathrm{~cm}$ ) were relative to a stable GPS base station installed by the USGS less than $2 \mathrm{~km}$ from the slide. Compared with GPS receivers using multiples frequencies (e.g., L1-L2), L1-only receivers typically are less expensive, have lower power requirements, and introduce less noise when satellite observables are processed using very short baselines (LaHusen et al. 2008). Processed differences in position at Oso were available to

Table 1 Notification/warning levels used during the 2014 Oso landslide monitoring period. Each level also included information about specific responsibilities and what actions should be taken (not shown here)

\begin{tabular}{|ll}
\hline Level 1 & \multicolumn{1}{c}{ Daily briefing } \\
\hline Level 2 & Small changes in monitoring trends \\
\hline Level 3 & Large or accelerated changes in monitoring trends observed \\
\hline Level 4 & Immediate action is necessary to evacuate one or more search and recovery divisions \\
\hline
\end{tabular}



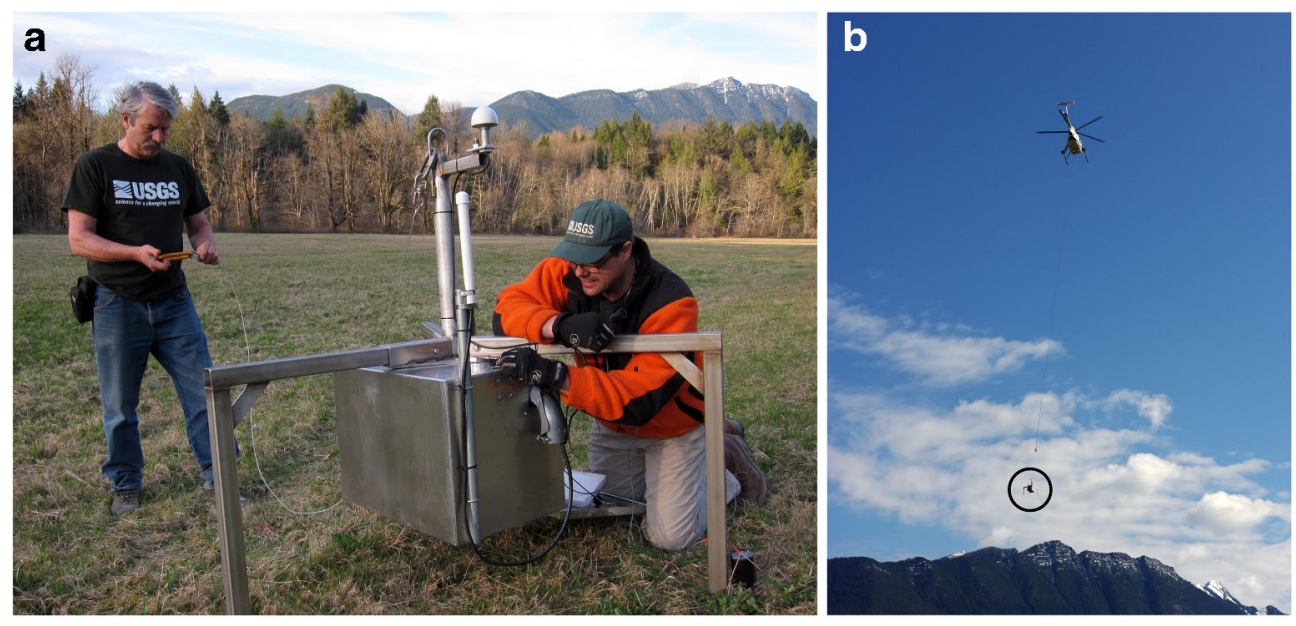

Fig. 7 Photographs showing (a) close-up and (b) helicopter deployment of USGS spider monitoring unit. Each spider unit contains an onboard GPS receiver, seismometer, and radio telemetry. Photos by M. Reid (USGS) taken on 31 March 2014 (a) and J. Godt (USGS) 1 April 2014 (b)

the Landslide Monitoring Team via a secure, nonpublic USGS website and summarized on the web-accessible near real-time dashboard.

Spider units also collected seismic data using external, singleaxis Sercel seismometer/geophones (model L-10 AR) with a natural frequency of $10 \mathrm{~Hz}$. These instruments were vertically buried to a depth of $\sim 0.5 \mathrm{~m}$ adjacent to the spiders, thus enabling direct contact with surficial materials. They could sense strong ground vibrations associated with any additional large upslope or adjacent slope failure. We collected seismic data at $100 \mathrm{~Hz}$; the Landslide Monitoring Team could view these data as waveforms, spectrograms, helicorder representations, and processed RSAM (Realtime Seismic Amplitude Measurement) data in close to real time over the internet. RSAM data are commonly used during volcanic eruptions as a predictive tool to track overall levels of seismicity (Endo and Murray 1991). At Oso, we used RSAM data (integrated over 10-s intervals) to potentially detect any increases in seismic activity resulting from increases in the frequency of smaller slides originating from the main Oso headscarp that might herald a larger retrogressive slope failure.

In addition to these two automated systems, WADNR geologists stationed at the Engineering Observation Lookout acted as realtime human spotters. These observers had an additional task to identify the timing and relative size of notable small failures from the main Oso headscarp - information used to help correlate these small failures with seismic records from the spider units and thus build on-site knowledge of how to interpret seismic signals. These size-to-seismic correlations were also aided by images taken every hour by a USGS time-lapse camera (Nikon D9o in a housing) positioned near the Engineering Observation Lookout.

\section{Repeat-assessment monitoring methods}

We also monitored ground-surface displacements using periodic surveying techniques on both regular and irregular intervals. Although these observations did not provide near real-time information, much of this surveying covered large areas and provided episodic time-series trends. The methods used at the Oso site included the following: stake-line surveying upslope of the main headscarp, total-station surveying of reflectors placed around the edge of that headscarp and on the slide mass, terrestrial laser scanning, repeat aerial lidar scans, and repeat aerial orthophotography (Figs. 5 and 6).

Snohomish County engineers used conventional surveying methods twice a day to measure three stake lines placed upslope of and perpendicular to the main head scarp. Survey observations from these lines were assessed daily to detect ground extension that might precede retrogressive failure above the main headscarp. Snohomish County also used total station survey methods to track the motion of prism reflectors placed at multiple locations (typically attached to large trees) around the upslope edge of the main headscarp and later on the slide mass itself. The total station instrument was located at the Engineering Observation Lookout across the valley from the slide (Fig. 6). Measurements of the reflectors were typically taken hourly and trends assessed daily. Survey data were provided to the Landslide Monitoring Team on a daily basis; however, information regarding any substantial changes were transmitted immediately via radio.

A series of repeat terrestrial laser scans (TLS), performed by WSDOT, helped us monitor both small (centimeter-scale) and large (meter-scale) topographic changes in the remaining main slide and headscarp areas, and to place other point surveying measurements into a spatial context. These oblique scans were collected on a weekly basis (Fig. 5) using an Optech ILRIS HD scanner from two ground locations on the east and west edges of the main slide (Fig. 6); data were processed using PolyWorks software. Due to limited scan locations, the resulting point cloud coverage typically included some areas with no laser returns, i.e., no data. Average laser point spacing was about $18 \mathrm{~cm}$. Elevation differences between the point clouds obtained from these repeat TLS surveys were computed and available to the Landslide Monitoring Team, typically within 1-2 days following the most recent TLS survey.

In addition to on-the-ground measurements, WSDOT obtained two aerial lidar-based digital elevation models (DEMs), one from 
data acquired 2 days after the slide event and the other from data acquired in early April. WSDOT also acquired multiple orthomosaics from vertical digital aerial photogrammetry (with $\sim 8 \mathrm{~cm}$ ground sampling distance) of the site (Fig. 5). Both lidar DEMs and orthomosaics were highly valuable for overall site characterization, localized assessments, and operational planning.

\section{Monitoring observations}

Although no additional large catastrophic slope failures occurred during the 5-week monitoring period, nor in the ensuing seven years, several other styles of failure did occur during our monitoring. Our methods implemented to detect precursors of large retrogressive failure upslope of the main headscarp, such as repeat surveys of stake lines and near real-time recording from extensometers (Fig. 6), revealed no trends in or significant amounts of ground displacement that would have caused recovery effort work stoppage. However, both our near real-time and repeat-assessment techniques detected smaller retrogressive, rapid debris falls from the headscarp and slow movement of the rotational slide block remaining downslope of the headscarp. These events were not threatening to recovery efforts. Here we present some of these monitoring observations, both to demonstrate the efficacy of these techniques in capturing smaller, potentially precursory events and to illustrate some typical failure behaviors we recorded. Graphs and images presented in the following sections serve to illustrate the data available during the actual response period and have not been modified other than the addition of some labels.

\section{Headscarp failures}

During our monitoring, relatively small $\left(\sim 100\right.$ to $\left.3000 \mathrm{~m}^{3}\right)$, retrogressive, rapid failures and small-scale sloughing typically occurred daily or multiple times a day on the $\sim 50^{\circ}$ headscarp of the main Oso landslide. Most of these shallow ( 1-3 $\mathrm{m}$ thick) landslides initiated in the recently exposed glacial outwash sands in the upper third of the scarp and deposited material at the base of the scarp into a graben formed by the downdropped upper block of the landslide. Some of these headscarp failures also contained more coherent glacial till that was exposed midway down the scarp face. Redundant and complementary monitoring techniques were effective in recording these small failures, including repeat terrestrial laser scans, time-lapse photography, repeat surveying of monuments placed at the top of the scarp, and continuous $100 \mathrm{~Hz}$ seismic monitoring. In addition, some of the headscarp failure events were witnessed by ground observers.

Elevation changes revealed by differencing DEMs acquired through repeat TLS scans clearly illustrate the locations and sizes of some of these small failures. Figure 8 shows the vertical elevation differences over a 2-week period, with pockets of erosion near the top of the scarp and corresponding deposition near the base of the scarp. The regions showing elevation differences on the scarp were likely the foci of one or several small failures. In addition, a few of the prism reflectors mounted on trees around the top of the headscarp showed slow displacement over the weeks of monitoring, although most were relatively stable. Some of these reflectors were eventually lost over the headscarp edge due to small retrogressive slope failures on the headscarp.

The timing of small-scale slope failures and sloughing on the headscarp was captured by seismometer/geophones on the spider units and later correlated with time-lapse photographs. RSAM measurements, which integrated seismic activity, provided a more unified method to monitor overall site activity, as illustrated in Fig. 9, and they also detected increases in headscarp failure activity. Overall site activity noise during daylight hours (Fig. 9) may have swamped signals generated by minor sloughing from the steep headscarp, but small retrogressive failures from the headscarp produced emergent seismic signals exceeding the background seismicity generated from recovery operations during daylight hours. Waveforms from geophones on the three spider units for one such event, on April 25, are shown in Fig. 10 (data available through IRIS). The event, documented in a video recorded by a nearby on-site geologist, consisted of a small headscarp failure in the upper outwash sands and underlying more coherent glacial till that slid, impacted, and travelled across the downslope remaining landslide deposit. About $15 \mathrm{~s}$ later (time 22:41:16 in Fig. 10), a larger topple composed of similar materials occurred; it also impacted, disaggregated the till into smaller blocks, and slid across the downslope main slide mass. These two small failures and transport of their deposits occurred over about $25 \mathrm{~s}$. Impacts from the two failures and subsequent shaking from debris disaggregation and sliding are clearly seen in the waveforms in Fig. 10. Interestingly, seismic responses from this small event helped characterize travel times from the landslide to nearby seismic stations and thus aided seismic analysis of the March 22 catastrophic failure (Iverson et al. 2015).

\section{Motion of the remaining landslide block}

Over the approximately 5 weeks of intensive monitoring, the large rotational mass remaining upslope of the recovery operations continued to displace slowly. Several techniques were used to document this slow motion, including periodic repeat TLS scans and near real-time L1 GPS positions obtained from the spider unit placed on this mass $\left(\mathrm{OSO}_{3}\right)$. Elevation differences in sequential DEMs constructed from repeat TLS scans (Fig. 8) indicated small displacements of the order of centimeters per week.

Using near real-time GPS positional data (Reid et al. 2021), we tracked the time history of landslide displacement. Figure 11 shows the $3 \mathrm{D}$ displacement over time from a spider located on the remaining landslide mass $\left(\mathrm{OSO}_{3}\right)$ and a curve fit to the data using locally weighted smoothing (LOWESS). It also shows two derivatives of displacement-velocity and acceleration-along with their corresponding LOWESS smoothed curves. These types of plots with derivatives were created periodically (not in near real-time) and made available to the Landslide Monitoring Team during the response. Also available were cumulative precipitation data from a rain gauge located upslope of the main headscarp. Several trends are notable in Fig. 11. Overall the average speed of the main slide mass was about $0.01 \mathrm{~m} /$ day (dashed line in Fig. 11 and categorized as "slow" on the Cruden and Varnes (1996) velocity scale). Over time, velocities decreased slightly, except after April 16 when small velocity or acceleration increases occurred during or shortly following modest pulses of rain (Fig. 11). Vertical GPS-derived displacements were similar to those obtained from differencing repeat TLS scans. Positional data from the other two GPSenabled spiders (OSO1 and $\mathrm{OSO}_{2}$ ) placed upslope of the headscarp and on the western slope were sparse, as the units were located in thick forest that resulted in poor GPS satellite visibility. Despite the relative paucity of GPS-derived positions from both of these spider 


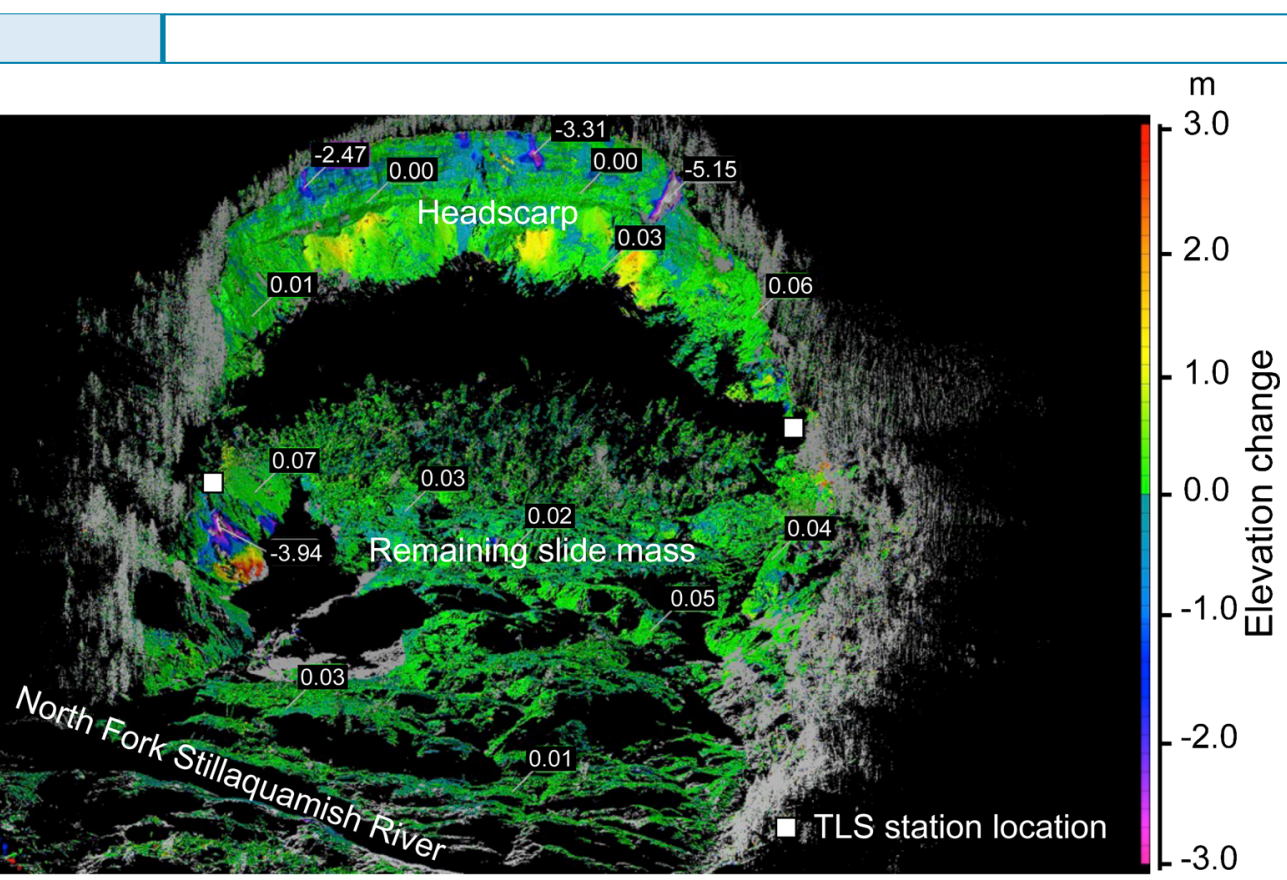

Fig. 8 Elevation differences over a 2-week period on the headscarp and remaining main mass of the Oso landslide obtained from repeat terrestrial laser scans (TLS). Small white numbers are local elevation differences in meters. Black areas indicate regions of no TLS data. Image available to the LMT during the landslide response, with notations added here

units, the data that were available indicated no appreciable motion.

Discussion of lessons learned

Responses to landslide crises can vary widely, ranging from the assessment of recent activity relative to past landslide events, to on-going monitoring of current movement, to collecting perishable data to aid future event forecasting (Collins et al. 2021). The 2014 Oso landslide response involved a combination of all these aspects. Lessons learned from our monitoring efforts that may aid future rapid responses and support crisis management include the following: (1) the necessity of ready-to-go technical capabilities; (2) the value of redundant sensors, on-site observers, and multiple techniques in a complete monitoring system; (3) the benefits of clear avenues of communication; and (4) the importance of continued research efforts to utilize near real-time data to provide adequate warning. We draw from the activities described above to illustrate these points.

\section{Need for technical capabilities}

To quickly evaluate and monitor an active landslide, landslide expertise and ready-to-deploy technical capabilities are needed. During the Oso event, many landslide experts from multiple agencies contributed to the monitoring efforts; these experts had a wide range of experience evaluating different styles of landsliding and their understanding of landslide processes directly aided search operations. Moreover, several of the agencies (USGS and WSDOT) had extensive capabilities in both installing and maintaining near real-time monitoring systems and detecting ground changes

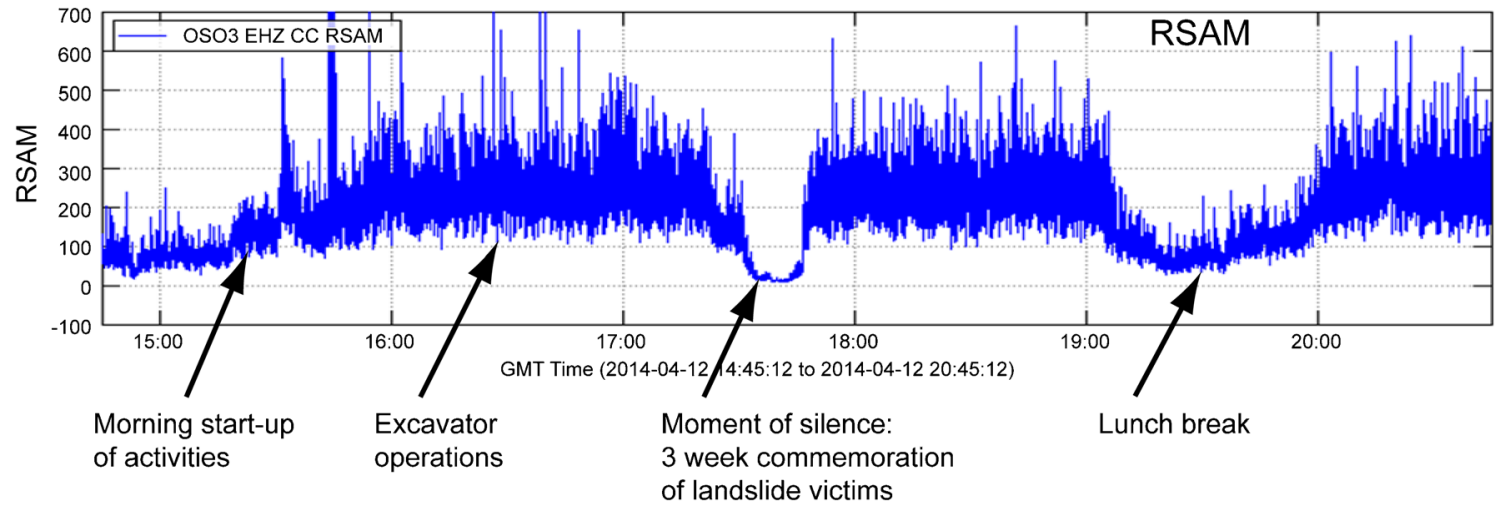

Fig. 9 Integrated seismic energy (over 10-s intervals) portrayed as RSAM (Real-time Seismic Amplitude Measurement) for a 6-h period (on 12 April 2014 ) recorded by a spider unit (OSO3) located on the remaining landslide mass 


\section{Original Paper}

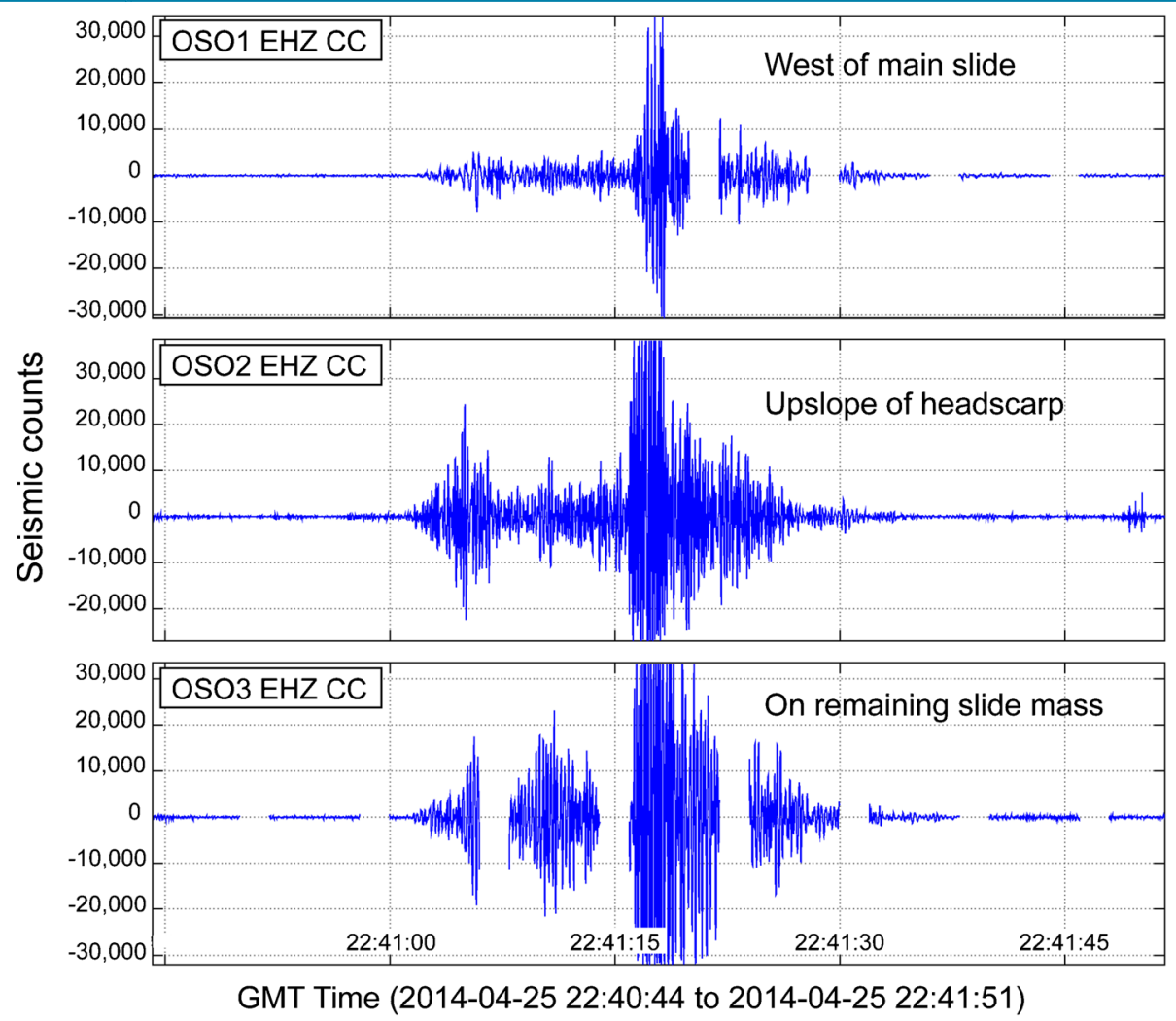

Fig. 10 Seismic waveforms generated by small headscarp failures on 25 April 2014 and recorded by geophones from three spider units (see Fig. 6 for locations). Energy units are shown as seismic counts. Short gaps in data are presumably from transmission losses

through repeat surveys. This wide-ranging experience, combined with having caches of ready-to-deploy equipment, enabled a rapid response. For example, USGS spider units had been previously deployed on other landslides (Harp et al. 2008) and units scheduled for installation on the Cleveland Corral landslide perched above U.S. Highway 50 in California were able to be readily diverted to Oso. We also found that a variety of complementary techniques allowed a more comprehensive view of landslide activity. The upslope survey lines and extensometers were crucial to assessing the potential for large-scale slide retrogression. Continuous GPS and repeat TLS scans detected motion of the remaining slide mass, whereas seismic analysis revealed the occurrence of smaller headscarp failures.

In addition, other types of landslide expertise were highly valuable during the Oso response. Crucial analyses, conducted off site, included the development of deposit thickness maps from lidar DEM differences, the assessment of past regional landslide activity (Haugerud 2014; Badger 2015), and the numerical simulation of landslide dynamics to guide search and recovery operations (Iverson et al. 2015; Iverson and George 2016). Due to the duration of continuous monitoring efforts, many different teams of USGS geologists rotated into positions with responsibility for constantly interpreting the incoming near real-time data. Not all these teams, however, had prior experience evaluating the monitoring observations and near real-time data streams. This lack led, in some cases, to minor misinterpretations of noise in the seismic and extensometer data which were subsequently corrected through training. This issue highlights the need for even experienced landslide responders to have direct familiarity with the types of data and anticipated behaviors detectable from the deployed monitoring systems.

Most landslide scientists do not have training in crisis response. Those providing technical advice to emergency managers during landslide crises would likely benefit from prior training in the Incident Command System (Phillips et al. 2011), which is used internationally. Given that postevent trauma following fatal events is relatively common, an awareness of incident stress and the techniques and resources used to manage such situations would be a valuable asset to landslide crisis responders (Everly Jr. et al. 2000).

Acknowledging this lesson, the USGS has added landslide technical expertise and monitoring capabilities in the years since the Oso event. These additions include having prescripted mission assignments for providing technical assistance to incident managers, as well as hiring a landslide seismologist and a landslide disaster response coordinator. The USGS has developed and performed training for a GPS-seismic spider system designed for rapid deployment, named LORAS (Landslide Optimized Realtime data Acquisition System). It has also acquired new instrumentation for remotely monitoring hazardous landslide sites, including long-range TLS capabilities. 

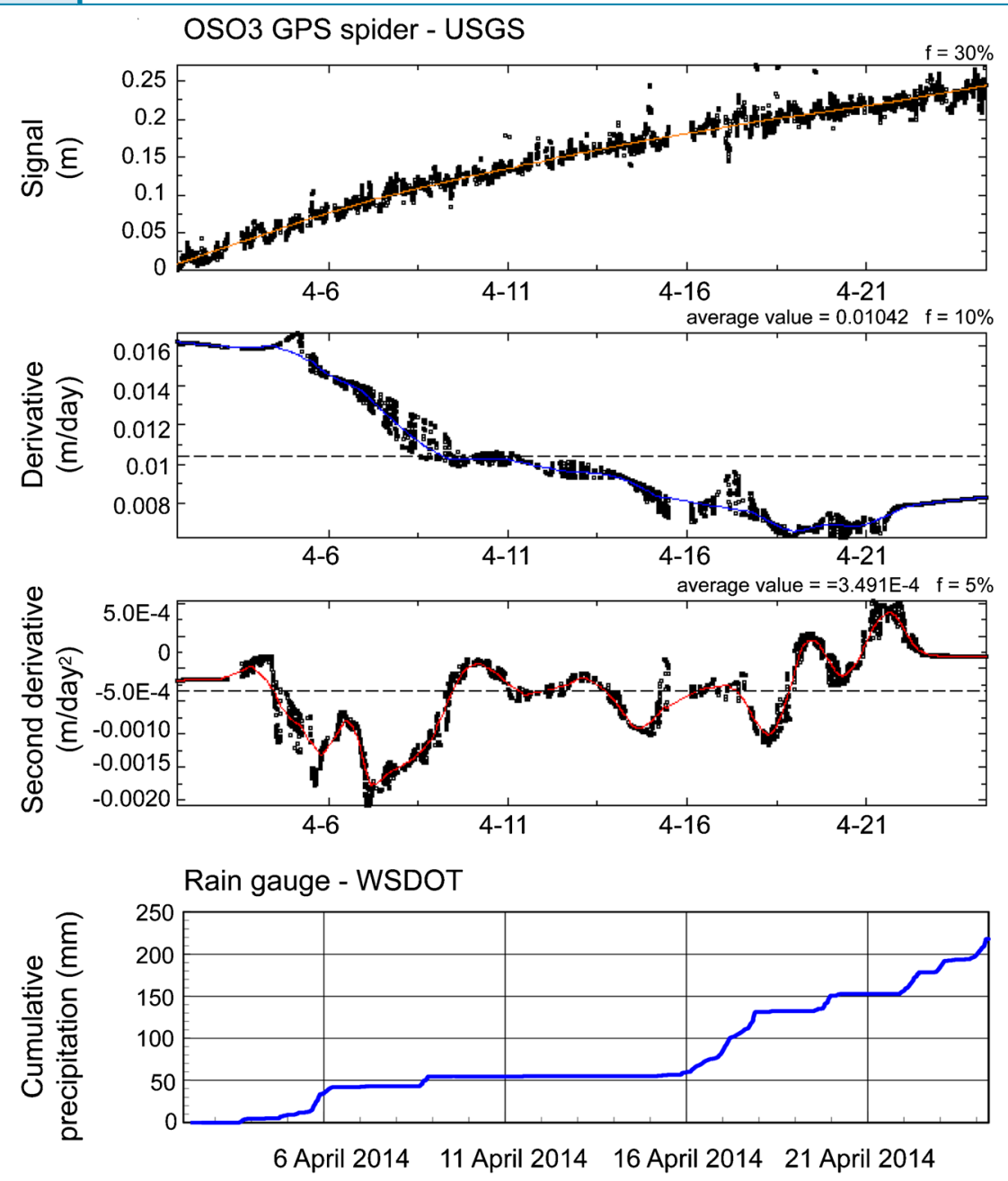

Fig. $113 \mathrm{D}$ downslope displacement (measured signal), velocity (derivative), and acceleration (second derivative) of the GPS-enabled spider (OSO3) on the remaining main Oso slide mass during April 2014. Fifteen-second epoch GPS data from the spider units were processed every 10 min. GPS data available in Reid et al. (2021). As derivatives are sensitive to noisy data, curve fits using LOWESS smoothing with $f$ percentages are shown. Precipitation data from rain gauge located above headscarp also shown. Data portrayed in local time

\section{Value of redundant techniques in a complete system}

Given the uncertainties in the general forecasting of large landslide behavior, as well as reliably predicting postevent Oso landslide behavior combined with the potential risks to hundreds of recovery workers from subsequent collapse, installing a robust and comprehensive monitoring system was paramount. We utilized multiple and somewhat redundant techniques with clearly defined monitoring objectives, namely, detecting precursory ground deformation that might precede additional large-scale, rapid slope failure. Moreover, we designed and deployed an end-to-end system that included field sensors, telemetry, a web-based Information Technology structure to capture and display data via the internet, and defined protocols with specific action items that depended on the level of slide activity. Use of different sensors with different telemetry systems combined with periodic ground and aerial lidar surveys enabled accurate assessment of current conditions. Because the various agencies involved already had experience with these techniques, they could be quickly deployed, and their data readily interpreted. System redundancy ensured the acquisition and availability of at least some current data, even if specific sensors malfunctioned or provided ambiguous results. Geologists stationed in the field were also a crucial element of the system. For example, if the origins of seismic signals were ambiguous in the incident command center, a quick call to the field observer often clarified the situation and calmed nerves regarding possible failures. Redundancy in monitoring data also reduced the uncertainty in assessing the landslide's current status and displacement trends.

Commonly used monitoring techniques that we considered deploying but did not included: ground-based (GB) radar techniques such as GB-InSAR (Casagli et al. 2010; Meier et al. 2016), DEM differencing using structure-from-motion (SfM) analysis of imagery from repeat drone or unmanned aerial vehicle (UAV) flights (Cook 2017; Warrick et al. 2019), and continuous near real-time video streaming of the landslide scarp and deposit. These techniques were not employed at Oso for various reasons. At the time, our ability to rapidly interpret ground-based radar data in near real-time was limited and, importantly, the estimated 
mobilization time for this type of monitoring was longer than the initial 2-week response window. Airspace over the slide area was highly restricted and most federal agencies at the time were legally unqualified to operate UAVs, thereby restraining drone usage. In addition, internet bandwidth needed for continuous video streaming at the relatively remote site was limited and in demand by various concurrent emergency uses. If these methods had been readily available, they could have aided our monitoring efforts. Instead, we focused on the value of implementing multiple techniques that we could rapidly deploy and readily interpret.

\section{Benefits of clearly defined communication channels}

In the chaos of a massive and deadly landslide disaster, clear lines of communication between the landslide experts and a variety of different audiences are crucial. On-site landslide experts typically need communication channels between other landslide experts, between the emergency response or local government managers, between their own agency or company managers, and between the public and news media. Moreover, conveying large uncertainties about future behavior requires different approaches for different audiences (e.g., DeGraff et al. 2015). During the Oso event, the Landslide Monitoring Team, composed of geologists and geotechnical engineers from the responding agencies, conducted daily meetings and conference calls to keep all team members informed about current activity levels. Members of the team that performed the previous day's continuous monitoring would prepare a summary of daily activities for the following day's meeting. Team members also had access to available monitoring data, including the near real-time data streams at all times, and could readily contact other team members with questions or concerns. This format worked well overall, incorporating diverse expertise and building crucial trust between geologists on the team. In hindsight, the approach might have benefitted by designating time to reassess the overall landslide status, such as potentially modifying the "nogo" line location in light of updated information. However, the large uncertainty about an ending date reduced the impetus to reevaluate earlier decisions.

During the monitoring phase of the Oso response, routine daily communications between the Landslide Monitoring Team and the emergency managers of the Incident Management Team directing the rescue and recovery operations were handled through one conduit-the geology liaison-this is typical of Incident Command System structures. Distilling scientific observations and expert opinions from the LMT into a cohesive and coherent message was an ongoing challenge and priority during the evolving crisis. This format worked quite well and also built trust between the LMT and IMT. In addition to routine communications, members of the LMT did have the ability to connect directly to field operation managers if landslide activity warranted an immediate evacuation.

During the response, communications with the public and news media about the landslide were typically handled through an onsite point-of-contact public affairs officer working with the IMT. Although this was an effective conduit for public briefings on recovery activities, the amount of scientific information conveyed about the landslide was limited. This led to a dearth of technical information released about the landslide event itself, and it contributed to unsubstantiated and widely disseminated speculation from other geologists not involved in the response. Although the
ICS structure has proven effective in many disaster responses, its strict control can create challenges for communication, data sharing, and access to a disaster location, particularly for academics and other interested parties. Later in the response, after the initial evaluation and monitoring deployment phase, the USGS did post current information and simulations on its web site. However, future responses could benefit from having a scientific public information plan in place at the onset, to keep the public and news media outlets better informed about the nature of the event. Since the Oso event, discussions between the USGS and academic researchers have focused on developing an organizational structure to better integrate hazard activities during future crisis response efforts, given liability and chain-of-command issues.

\section{Importance of research efforts for warning}

Despite the widespread use of landslide monitoring, forecasting rapid failure using monitoring data remains an active research area. Such forecasting is fraught with uncertainty, even with multiple near real-time data streams. To better understand landslide movement behavior, large investigative monitoring networks using sophisticated surface and subsurface monitoring techniques have been deployed at sites such as Randa, Switzerland (Loew et al. 2012), Turtle Mountain, Canada (Froese et al. 2012), and Åknes, Norway (Blikra 2012). However, time and resources are required to construct these extensive networks and a past record of landslide activity is needed to enable confident behavior forecasting. During a landslide crisis, both of these are absent. Responders in an emergency effort do not have the luxury of collecting observations, analyzing data, and then developing models and failure criteria.

In most cases, the inability to accurately forecast landslide behavior during a rapid response is due to gaps in scientific knowledge about the meaning of broad landslide movement patterns and to a lack of knowledge about site-specific conditions. A variety of factors influence the propensity for rapid, catastrophic failure, including material properties and slide geometry (e.g., Fell et al. 2007). In general, a moving landslide is of more concern than a static hillslope and an accelerating landslide is of more concern than one with steady or decelerating motion. Beyond these simplistic rules-of-thumb, landslide behaviors can vary greatly. This uncertainty emphasizes the need to adapt any responses to changing conditions in the extent and amount of landslide activity.

To address near real-time forecasting needs, a wide spectrum of researchers have advocated that specific patterns in velocity, the reciprocal of velocity, or acceleration of a moving mass can reliably predict the timing of rapid, catastrophic failure (e.g., Saito 1965; Varnes 1983; Fukuzono 1985; Salt 1988; Voight 1989; Crosta and Agliardi 2003; Rose and Hungr 2007; Federico et al. 2012; Dick et al. 2015; Segalini et al. 2018; Intrieri et al. 2019; Chen and Jiang 2020). Because near real-time data can be noisy, other investigators have developed supplemental techniques to enable more accurate time-of-failure predictions (e.g., Intrieri and Gigli 2016; Manconi and Giordan 2016; Carlà et al. 2017; Zhang et al. 2020; Zhou et al. 2020). Despite notable successes, approaches based on velocity or acceleration patterns have not always led to reliable timing forecasts for all slides (e.g., Petley et al. 2002; Rose and Hungr 2007; Dick et al. 2015; Intrieri and Gigli 2016). The amount of accumulated strain prior to catastrophic failure is also of concern and laden with uncertainty, particularly in materials susceptible to rapid strength loss under large strains. 
A landslide crisis is a difficult environment in which to divine patterns and forecast behavior. Instead, research efforts to construct a framework for assessing potential behaviors are needed beforehand. Advanced monitoring techniques, such as TLS, GPS, ground-based radar, SfM, and seismic analysis, can provide a plethora of information about landslide activities, including the detection of precursory deformation and seismic activity. Nevertheless, the overarching challenge is to forecast landslide behavior using data obtained in near real-time.

\section{Conclusions}

The rapid failure of the Oso landslide in March 2014 resulted in a deadly, highly mobile debris avalanche-flow. For weeks following the event, hundreds of workers toiled beneath the landslide scar, unable to avoid potential exposure from any additional slope failures. Using the monitoring experiences of multiple governmental agencies, we quickly installed several near real-time systems and performed numerous episodic surveys to detect any precursory ground movement that might provide advance warning of another catastrophic slope failure. We found that total station surveying methods, repeat TLS scans, extensometers, continuous GPS, seismic monitoring, and on-site observers each provided crucial information. Absent the technical guidance and monitoring information provided to emergency managers at Oso, search and recovery operations would have been operating with greater uncertainty, potentially affecting their efficiency and safety. Lessons learned from this case-study include the following: (1) the need for preexisting technical expertise and ready-to-deploy capabilities; (2) the value of redundant monitoring techniques in a complete system; (3) the benefits of clearly defined lines of communication; and (4) the importance of research efforts to improve forecasting of landslide behavior and issuance of appropriate warnings, particularly using near real-time data streams. These lessons should prove beneficial in future landslide crises.

\section{Acknowledgements}

The authors would like to acknowledge and thank the many geologists, hydrologists, and engineers that participated in and supported monitoring efforts at the Oso landslide in the months following the disaster. Specifically, we thank Dale Topham and Jeff Jones of Snohomish County Public Works, Washington for their steadfast assistance and overall support during the landslide monitoring. Geologists that assisted in the field include Bryan Garcia, Casey Hanell, John Jenkins, John McKenzie, Eli Newbie, David Norman, Rian Skov, and Tim Walsh (all from Washington State Department of Natural Resources) and Kirk Bailey (Snohomish County). Bob Grandorf (Washington State Department of Transportation) was crucial in installing and maintaining the extensometer and rain gauge near real-time data acquisition system. Chris Lockett, Ben Pauk, and Kelly Swinford (all from U.S. Geological Survey [USGS]) assisted with installing the GPS-seismic spider monitoring system. Adam Mosbrucker (USGS) set up the timelapse photography, and Mike Randall (USGS) developed the webbased monitoring dashboard. Kate Allstadt (University of Washington's Pacific Northwest Seismic Network-now with USGS) played a lead role in interpreting seismicity following the Oso event. Seismic waveform data from the USGS spiders (OSO1, $\mathrm{OSO}_{2}, \mathrm{OSO}_{3}$ ) are available through the IRIS Data Management Center (https://ds.iris.edu/mda/CC/OSO$/$ for the $\mathrm{OSO}_{3}$ spider, with similar URL naming conventions for the other spiders). IRIS Data Services are funded through the Seismological Facilities for the Advancement of Geoscience and EarthScope (SAGE) Proposal of the U.S. National Science Foundation under Cooperative Agreement EAR-1261681. Kate Allstadt (USGS), Jason Kean (USGS), and an anonymous reviewer helped improve this manuscript. Finally, we would like to thank all those who contributed to the Oso emergency response, including first responders, local volunteers, and recovery teams. Author affiliations reflect their employing institutions at the time of the Oso response. Supplemental funding for monitoring equipment and response efforts was provided by a Mission Assignment from the U.S. Federal Emergency Management Agency (FEMA). Any use of trade, firm, or product names is for descriptive purposes only and does not imply endorsement by the U.S. Government.

\section{Declarations}

No conflicts of interest are noted. GPS monitoring data from the USGS spider units are available in the Reid et al. (2021) data release cited in the manuscript. Seismic monitoring data from the USGS spider units are available through IRIS. All authors contributed to the Oso landslide response and commented on previous versions of the manuscript.

Open Access This article is licensed under a Creative Commons Attribution 4.0 International License, which permits use, sharing, adaptation, distribution and reproduction in any medium or format, as long as you give appropriate credit to the original author(s) and the source, provide a link to the Creative Commons licence, and indicate if changes were made. The images or other third party material in this article are included in the article's Creative Commons licence, unless indicated otherwise in a credit line to the material. If material is not included in the article's Creative Commons licence and your intended use is not permitted by statutory regulation or exceeds the permitted use, you will need to obtain permission directly from the copyright holder. To view a copy of this licence, visit http://creativecommons.org/licenses/by/ $4.0 \%$

\section{References}

Aaron J, Hungr 0, Stark TD, Baghdady AK (2017) Oso, Washington, Landslide of March 22, 2014: dynamic analysis. J Geotech Geoenviron 143:05017005. https://doi.org/ 10.1061/(ASCE)GT.1943-5606.0001748

Allasia P, Manconi A, Giordan D, Baldo M, Lollino G (2013) ADVICE: a new approach for near-real-time monitoring of surface displacements in landslide hazard scenarios. Sensors 13:8285-8302. https://doi.org/10.3390/s130708285

Allstadt K, Malone S, Vidale J, Bodin P, Steele B (2014) Seismic signals generated by the Oso landslide. Posted by the Pacific Northwest Seismic Network, March 26, 2014

Anderson SW, Mackenzie KK, Magirl CS, Wallick JR, Mastin MC, Foreman JR (2017) Geomorphic response of the North Fork Stillaguamish River to the State Route 530 landslide near Oso, Washington. U S Geol Surv Sci Inv Rep:2017-5055. https:// doi.org/10.3133/sir20175055

Angeli MG, Pasuto A, Silvano S (2000) A critical review of landslide monitoring experiences. Eng Geol 55:133-147. https://doi.org/10.1016/S0013-7952(99)00122-2

Asahi Shimbun T (2014a) Hiroshima honors firefighter killed in landslide while helping others to safety, 19 November 2014. Japan

Asahi Shimbun T (2014b) Pre-dawn landslides kill 36 in Hiroshima, 7 remain missing, 20 August 2014. Japan

Asahi Shimbun T (2015) Lanterns lit to mourn those killed in Hiroshima mudslides, 21 August 2015. Japan 
Badger TC (2015) SR 530 MP 35 to 41 geotechnical study. Washington State Department of Transportation, Olympia, Washington

Badger TC, D'Ignazio M (2018) First-time landslides in Vashon advance glaciolacustrine deposits, Puget Lowland, U.S.A. Eng Geol 243:294-307. https://doi.org/10.1016/ j.enggeo.2018.07.011

Badger TC, Smith EL, Lowell SM (2011) Failure mechanics of the Nile Valley Landslide, Yakima County, Washington. Environ Eng Geosci 17:353-376. https://doi.org/ 10.2113/gseegeosci.17.4.353

Blikra LH (2012) The Åknes rockslide, Norway. In: Clague JJ, Stead D (eds) Landslides: types, mechanisms and modeling. Cambridge University Press, Cambridge, pp 323335

Carlà T, Intieri E, Di Traglia F, Nolesini T, Gigli G, Casagli N (2017) Guidelines on the use of inverse velocity method as a tool for setting alarm thresholds and forecasting landslides and structure collapses. Landslides 14:517-534. https://doi.org/10.1007/ s10346-016-0731-5

Casagli N, Catani F, Del Ventisette C, Luzi G (2010) Monitoring, prediction, and early warning using ground-based radar interferometry. Landslides 7:291-301. https:// doi.org/10.1007/s10346-010-0215-y

Chen M, Jiang Q (2020) An early warning system for integrating time-of-failure analysis and alert procedure for slope failures. Eng Geol 272:105629. https://doi.org/10.1016/ j.enggeo.2020.105629

Coe JA, Baum RL, Allstadt KE, Kochevar BF Jr, Schmitt RG, Morgan ML, White JL, Stratton BT, Hayashi TA, Kean JW (2016) Rock-avalanche dynamics revealed by large-scale field mapping and seismic signals at a highly mobile avalanche in the West Salt Creek valley, western Colorado. Geosphere 12:1-25. https://doi.org/10.1130/GES01265.1

Collins BD, Reid ME (2020) Enhanced landslide mobility by basal liquefaction: the 2014 State Route 530 (Oso), Washington, landslide. Geol Soc Am Bull 132:451-476. https:// doi.org/10.1130/B35146.1

Collins BD, Reid ME, Coe JA, Kean JW, Baum RL, Jibson RW, Godt JW, Slaughter SL, Stock GM (2021) Progress and lessons learned from responses to landslide disasters. In: Sassa K, Mikoš M, Sassa S, Bobrowsky PT, Takara K, Dang K (eds) Understanding and reducing landslide disaster risk, Sendai Landslide Partnerships and Kyoto Landslide Commitment, vol 1. Springer International Publishing, Cham, pp 85-111. https:// doi.org/10.1007/978-3-030-60196-6_4

Cook KL (2017) An evaluation of the effectiveness of low-cost UAVs and structure from motion for geomorphic change detection. Geomorph 278:195-208. https://doi.org/ 10.1016/j.geomorph.2016.11.009

Crosta GB, Agliardi F (2003) Failure forecast for large rock slides by surface displacement measurements. Can Geotech J 40:176-191. https://doi.org/10.1139/t02-085

Cruden DM, Varnes DJ (1996) Landslide types and processes. In: Turner AK, Schuster RL (eds) Landslides: investigation and mitigation, Special Report 247. Transportation Research Board, Washington, D. C., pp 36-75

DeGraff JV, Gallegos AJ, Reid ME, LaHusen RG, Denlinger RP (2015) Using monitoring and modeling to define the hazard posed by the reactivated Ferguson rock slide, Merced Canyon, California. Nat Hazards 76:769-789. https://doi.org/10.1007/s11069-0141518-4

Dick GJ, Eberhardt E, Cabrejo-Liévano AG, Stead D, Rose ND (2015) Development of an early-warning time-of-failure analysis methodology for open-pit mine slopes utilizing ground-based slope stability radar monitoring data. Can Geotech J 54:515-529. https://doi.org/10.1139/cgj-2014-0028

Dragovich JD, Stanton BW, Lingley JWS, Griesel GA, Polenz M (2003) Geologic map of the Mount Higgins 7.5-minute quadrangle, Skagit and Snohomish Counties, Washington. Washington Division of Geology and Earth Resources, Open File Report 2003-11

Dunnicliff J (1993) Geotechnical instrumentation for monitoring field performance. John Wiley \& Sons, New York

Eberhardt E, Clague JJ, Stead D (2012) Landslide monitoring: the role of investigative monitoring to improve understanding and early warning of failure. In: Clague J, Stead D (eds) Landslides: types, mechanisms and modeling. Cambridge University Press, Cambridge, pp 222-234

Endo ET, Murray T (1991) Real-time Seismic Amplitude Measurement (RSAM): a volcano monitoring and prediction tool. Bull Volcanol 53:533-545. https://doi.org/10.1007/ BF00298154

Everly GS Jr, Flannery RB Jr, Mitchell JT (2000) Critical incident stress management (CISM): a review of the literature. Aggress Violent Behav 5:23-40. https://doi.org/ 10.1016/S1359-1789(98)00026-3

Federico A, Popescu M, Elia G, Fidelibus C, Internò G, Murianni A (2012) Prediction of time to slope failure: a general framework. Environ Earth Sci 66:245-256. https:// doi.org/10.1007/s12665-011-1231-5

Fell R, Glastonbury J, Hunter G (2007) Rapid landslides: the importance of understanding mechanisms and rupture surface mechanics. Q J Eng Geol Hydrogeol 40:9-27
Froese CR, Charriere M, Humair F, Jaboyedoff M, Pedrazzini A (2012) Characterization and management of rockslide hazard at Turtle Mountain, Alberta, Canada. In: Clague J, Stead D (eds) Landslides: types, mechanisms and modeling. Cambridge University Press, Cambridge, pp 310-322

Froese CR, Moreno F (2014) Structure and components for the emergency response and warning system on Turtle Mountain, Alberta, Canada. Nat Hazards 70:1698-1712. https://doi.org/10.1007/s11069-011-9714-y

Fukuzono T (1985) A method to predict the time of slope failure caused by rainfall using the inverse number of velocity of surface displacement. J Japan Landslide Society 22:8-13

Fukuzono T (1990) Recent studies on time prediction of slope failure. Landslide News 4:9-12

Graham-Harrison E (2014) Afghanistan mudslides: hundreds feared dead, 2 May 2014. United Kingdom

Harp EL, Reid ME, Godt JW, DeGraff JV, Gallegos AJ (2008) Ferguson rock slide buries California State Highway near Yosemite National Park. Landslides 5:331-337. https:// doi.org/10.1007/s10346-008-0120-9

Haugerud RA (2014) Preliminary interpretation of pre-2014 landslide deposits in the vicinity of Oso, Washington. U S Geol Surv Open-File Rep:2014-1065

Henn B, Cao Q, Lettenmaier DP, Magirl CS, Mass C, Brent Bower J, Laurent MS, Mao Y, Perica S (2015) Hydroclimatic conditions preceding the March 2014 Oso landslide. J Hydrometeorol 16:1243-1249. https://doi.org/10.1175/JHM-D-15-0008.1

Hibert C, Stark CP, Ekström G (2015) Dynamics of the Oso-Steelhead landslide from broadband seismic analysis. Nat Hazard Earth Sys 15:1265-1273. https://doi.org/ 10.5194/nhess-15-1265-2015

Intrieri E, Carlà T, Gigli G (2019) Forecasting the time of failure of landslides at slopescale: A literature review. Earth Sci Rev 193:333-349. https://doi.org/10.1016/ j.earscirev.2019.03.019

Intrieri E, Gigli G (2016) Landslide forecasting and factors influencing predictability. Nat Hazards Earth Syst Sci 16:2501-2510. https://doi.org/10.5194/nhess-16-2501-2016

Intrieri E, Gigli G, Casagli N, Nadim F (2013) Brief communication "Landslide Early Warning System: toolbox and general concepts". Nat Hazards Earth Syst Sci 13:8590. https://doi.org/10.5194/nhess-13-85-2013

Intrieri E, Gigli G, Mugnai F, Fanti R, Casagli N (2012) Design and implementation of a landslide early warning system. Eng Geol 147:124-136. https://doi.org/10.1016/ j.enggeo.2012.07.017

Iverson RM (2000) Landslide triggering by rain infiltration. Water Resour Res 207:59-82. https://doi.org/10.1029/2000WR900090

Iverson RM, George DL (2016) Modeling landslide liquefaction, mobility bifurcation and the dynamics of the 2014 Oso disaster. Géotechnique 66:175-187. https://doi.org/ 10.1680/jgeot.15.LM.004

Iverson RM, George DL, Allstadt K, Reid ME, Collins BD, Vallance JW, Schilling SP, Godt JW, Cannon CM, Magirl CS, Baum RL, Coe JA, Schulz WH, Bower JB (2015) Landslide mobility and hazards: implications of the 2014 Oso disaster. Earth Planet Sc Lett 412:197-208. https://doi.org/10.1016/j.epsl.2014.12.020

Iverson RM, Reid ME, LaHusen RG (1997) Debris-flow mobilization from landslides. Annu Rev Earth PI Sc 25:85-138. https://doi.org/10.1146/annurev.earth.25.1.85

Jaboyedoff M, Oppikofer T, Abellán A, Derron MH, Loye A, Metzger R, Pedrazzini A (2012) Use of LIDAR in landslide investigations: a review. Nat Hazards 61:5-28. https:// doi.org/10.1007/s11069-010-9634-2

Jibson RW (1992) The Mameyes, Puerto Rico, landslide disaster of October 7, 1985. In: Slosson JE, Keene AG, Johnson JA (eds) Landslides/landslide mitigation, Geol Soc Am Rev in Eng Geology, vol IX. Boulder, Colorado, pp 37-54

Keaton JR, Wartman J, Anderson SA, Benoît J, dela Chapelle J, Gilbert R, Montgomery DR (2014) The 22 March 2014 Oso landslide,Washington, Geotechnical Extreme Events Reconnaissance Association Report GEER-036

Keys JR, Green PM (2008) Ruapehu Lahar New Zealand 18 March 2007: lessons for hazard assessment and risk mitigation 1995-2007. J Disaster Res 3:284-296

Kilburn CRJ, Petley DN (2003) Forecasting giant, catastrophic slope collapse: lessons from Vajont, Northern Italy. Geomorph 54:21-32. https://doi.org/10.1016/S0169555X(03)00052-7

LaHusen RG (2005) Debris-flow instrumentation. In: Jakob M, Hungr 0 (eds) Debris-flow hazards and related phenomena. Praxis, Springer, Berlin, pp 291-304

LaHusen RG, Swinford KJ, Logan M, Lisowski M (2008) Instrumentation in remote and dangerous settings; examples using data from GPS "spider" deployments during the 2004-2005 eruption of Mount St. Helens, Washington. In: Sherrod DR, Scott WE, Stauffer PH (eds) A volcano rekindled: the renewed eruption of Mount St. Helens, 2004-2006, U S Geol Surv Prof Paper 1750. https://doi.org/10.3133/pp175016

Loew S, Gischig V, Willenberg H, Alpiger A, Moore JR (2012) Randa: kinematics and driving mechanisms of a large complex rockslide. In: Clague JJ, Stead D (eds) 
Landslides: types, mechanisms and modeling. Cambridge University Press, Cambridge, pp 297-309

Loew S, Gschwind S, Gischig V, Keller-Signer A, Valenti G (2016) Monitoring and early warning of the 2012 Preonzo catastrophic rockslope failure. Landslides 14:141-154. https://doi.org/10.1007/s10346-016-0701-y

Lu N, Godt JW (2013) Hillslope hydrology and stability. Cambridge University Press, Cambridge

Malet J-P, Ulrich P, Deprez A, Masson F, Lissak C, Maquaire 0 (2013) Continuous monitoring and near-real time processing of GPS observations for landslide analysis: a methodological framework. In: Landslide science and practice, vol 2. SpringerVerlag, Berlin Heidelberg, pp 201-209

Manconi A, Giordan D (2016) Landslide failure forecast in near-real-time. Geomat Nat Hazards Risk 7:639-648. https://doi.org/10.1080/19475705.2014.942388

Mazzanti P (2012) Remote monitoring of deformation. An overview of the seven previous methods described in previous GINs. Geotechnical Instrumentation News:24-29

Meier L, Jacquemart M, Blattmann B, Wyssen S, Arnold B, Funk M (2016) Radar-based warning and alarm systems for Alpine mass movements. In: 13th Congress Interpraevent 2016: living with natural risks, 30 May to 2 June 2016, Lucerne, Switzerland, 2016. International Research Society INTERPRAEVENT, pp 960-968

Mikkelsen PE (1996) Field instrumentation. In: Turner AK, Schuster RL (eds) Landslides: investigation and mitigation, Special Report 247. National Academy Press, Washington, pp 278-316

Miller DJ, Sias J (1997) Environmental factors affecting the Hazel landslide. M2 Environmental Services, Report to Washington Department of Natural Resources

Miller DJ, Sias J (1998) Deciphering large landslides: linking hydrological, groundwater and slope stability models through GIS. Hydrol Process 12:923-941. https://doi.org/ 10.1002/(SICI)1099-1085(199805)12:6<923::AID-HYP663>3.0.C0;2-3

Norrish NI, Mikkelsen PE, Lowell SM, Badger TC (2011) Slope deformation monitoring of rock excavations, Interstate 90, Snoqualmie Pass, Washington. In: Eberhardt E, Stead D (eds) International Symposium on Rock Slope Stability in Open Pit Mining and Civil Engineering. Vancouver, Canada

Pankow KL, Moore JR, Hale JM, Koper KD, Kubacki T, Whidden KM, McCarter MK (2014) Massive landslide at Utah copper mine generates wealth of geophysical data. GSA Today 24:4-9. https://doi.org/10.1130/GSATG191A.1

Pecoraro G, Calvello M, Piciullo L (2019) Monitoring strategies for local landslide early warning systems. Landslides 16:213-231. https://doi.org/10.1007/s10346-018-1068-z

Perkins JP, Reid ME, Schmidt KM (2017) Control of landslide volume and hazard by glacial stratigraphic architecture, northwest Washington State, USA. Geology 45:1139-1142. https://doi.org/10.1130/G39691.1

Petley DN, Bulmer MH, Murphy W (2002) Patterns of movement in rotational and translational landslides. Geology 30:719-722. https://doi.org/10.1130/00917613(2002)030<0719:POMIRA > 2.0.C0;2

Phillips BD, Neal DM, Webb G (2011) Introduction to emergency management. CRC Press

Read RS et al (2005) Frank slide a century later: The Turtle Mountain monitoring project. In: Hungr 0, Fell R, Couture RR, Eberhardt E (eds) Landslide risk management. AA Balkema, Leiden, Netherlands, pp 713-723

Reid ME, Baum RL, LaHusen RG, Ellis WL (2008) Capturing landslide dynamics and hydrologic triggers using near-real-time monitoring. In: Chen Z, Zhang J, Li Z, Wu F, Ho K (eds) Landslides and engineered slopes: from the past to the future, Xi'an, China. Taylor \& Francis Group, pp 179-191

Reid ME, LaHusen RG (1998) Real-time monitoring of active landsides along Highway 50, El Dorado County. Calif Geol 51:17-20

Reid ME, LaHusen RG, Baum RL, Kean JW, Schulz WH, Highland LM (2012) Real-time monitoring of landslides. U S Geol Surv Fact Sheet, pp 2012-3008

Reid ME, LaHusen RG, Lockett C (2021) GPS monitoring data from spider units on the post-disaster 2014 Oso landslide, Snohomish County, Washington, US Geological Survey data release. https://doi.org/10.5066/P9TTJFGU

Riemer MF, Collins BD, Badger TC, Toth C, Yu YC (2015) Geotechnical soil characterization of intact Quaternary deposits forming the March 22, 2014 SR-530 (Oso) landslide, Snohomish County, Washington. U S Geol Surv Open-File Rep 2015-1089. https:// doi.org/10.3133/ofr20151089

Rose ND, Hungr 0 (2007) Forecasting potential rock slope failure in open pit mines using the inverse-velocity method. Int J Rock Mech Min Sci 44:308-320

Saito M (1965) Forecasting the time of occurrence of slope failure. Proc Sixth ICSMFE, Montreal 2:537-541

Salt G (1988) Landslide mobility and remedial measures. In: Bonnard C (ed) Landslides: Glissements de Terrain, Proceedings of the Fifth International Symposium on Landslides, vol 1. A. A. Balkema, Rotterdam, pp 757-762

Scaioni M (ed) (2015) Modern technologies for landslide monitoring and prediction. Springer
Segalini A, Valletta A, Carri A (2018) Landslide time-of-failure forecast and alert threshold assessment: a generalized criterion. Eng Geol 245:72-80. https://doi.org/10.1016/ j.enggeo.2018.08.003

SR530 Landslide Commission (2014) Final Report. Office of the Governor, Olympia, Wash. Stark TD, Baghdady AK, Hungr 0, Aaron J (2017) Case study: Oso, Washington, Landslide of March 22, 2014 - Material properties and failure mechanism. J Geotech Geoenviron 143:05017001. https://doi.org/10.1061/(ASCE)GT.1943-5606.0001615

Thorsen GW (1969) Landslide of January 1967 which diverted the North Fork of the Stillaguamish River near Hazel: Memorandum dated November 28, 1969 to Marshall T. Huntting. Department of Natural Resources, Geology \& Earth Resources Division, Olympia, Washington

UN Working Group (2016) Report of the open-ended intergovernmental expert working group on indicators and terminology relating to disaster risk reduction.

Varnes DJ (1983) Time-deformation relations in creep to failure of earth materials. Proc of the 7th Southeast Asian Geotechnical Conference 2:107-130

Voight B (1989) A relation to describe rate-dependent material failure. Science 243:200203. https://doi.org/10.1126/science.243.4888.200

Warrick JA, Ritche AC, Schmidt KM, Reid ME, Logan J (2019) Characterizing the catastrophic 2017 Mud Creek landslide, California, using repeat structure-frommotion (SfM) photogrammetry. Landslides 16:1201-1219. https://doi.org/10.1007/ s10346-019-01160-4

Wartman J, Montgomery DR, Anderson SA, Keaton JR, Benoît J, dela Chapelle J, Gilbert R (2016) The 22 March 2014 Oso landslide, Washington, USA. Geomorph 253:275-288. https://doi.org/10.1016/j.geomorph.2015.10.022

White JL, Morgan ML, Berry KA (2015) The West Salt Creek landslide: a catastrophic rockslide and rock/debris avalanche in Mesa County, Colorado. Colorado Geological Survey Bulletin 55, 45 p, 2 plates

Williams DM et al. (2020) U.S. Geological Survey 2018 Kilauea volcano eruption response in Hawai'i-after-action review. U.S. Geological Survey Open-File Report 2020-1041. https://doi.org/10.3133/ofr20201041

Yin Y, Wang H, Youlong G, Xiaochun L (2010) Real-time monitoring and early warning of landslides at relocated Wushan Town, the Three Gorges Reservoir, China. Landslides 7:339-349. https://doi.org/10.1007/s10346-010-0220-1

Zhang J, Wang ZP, Zhang GD, Xue YD (2020) Probabilistic prediction of slope failure time. Eng Geol 271:105586. https://doi.org/10.1016/j.enggeo.2020.105586

Zhou XP, Liu LJ, Xu C (2020) A modified inverse-velocity method for predicting the failure time of landslides. Eng Geol 268:105521. https://doi.org/10.1016/ j.enggeo.2020.105521

M. E. Reid $(\square)$ - B. D. Collins - K. M. Schmidt

Landslide Hazards Program,

U.S. Geological Survey,

350 North Akron Road, Moffett Field, CA 94035, USA

Email: mreid@usgs.gov

J. W. Godt - W. H. Schulz · R. L. Baum - J. A. Coe · E. L. Harp · J. B. Smith Geologic Hazards Science Center,

U.S. Geological Survey,

Box 25046, MS 966, Denver, C0 80225, USA

R. G. LaHusen · R. M. Iverson · D. L. George

Cascades Volcano Observatory,

U.S. Geological Survey,

1300 SE Cardinal Court, Bldg. 10, Vancouver, WA 98683, USA

\section{S. L. Slaughter}

Washington State Department of Natural Resources,

1111 Washington Street SE, Olympia, WA 98504, USA

\section{T. C. Badger}

Materials Lab - Geotechnical Services,

Washington State Department of Transportation,

P.0. Box 47365, Olympia, WA 98504, USA

\section{R. A. Haugerud}

Geology, Energy, Minerals, and Geophysics Science Center,

U.S. Geological Survey,

310 Condon Hall, Room 124, Seattle, WA 98195, USA 